University of Wollongong

Research Online

Faculty of Engineering and Information

Faculty of Engineering and Information

Sciences - Papers: Part A

Sciences

$1-1-2017$

Experimental investigation and simplified modeling of response of steel plates subjected to close-in blast loading from spherical liquid explosive charges

Alex M. Remennikov

University of Wollongong, alexrem@uow.edu.au

Tuan D. Ngo

University of Melbourne

Damith Mohotti

University of Sydney

Brian Uy

University of Sydney, brianuy@uow.edu.au

Michael Netherton

University of Newcastle

Follow this and additional works at: https://ro.uow.edu.au/eispapers

Part of the Engineering Commons, and the Science and Technology Studies Commons

Research Online is the open access institutional repository for the University of Wollongong. For further information contact the UOW Library: research-pubs@uow.edu.au 


\title{
Experimental investigation and simplified modeling of response of steel plates subjected to close-in blast loading from spherical liquid explosive charges
}

\author{
Abstract \\ Detonations of nitromethane spherical charges have been carried out to study close-in blast loading of \\ steel plates and the effectiveness of several protective solutions. Three types of bare steel plates, namely \\ mild steel, high-strength steel, and stainless steel were subjected to explosive blast loading. Steel plates \\ of the same type with polyurea coating and composite covers were also subjected to localized blast \\ loading. During an explosive field trial, the blast pressures and displacements of steel plates were \\ measured. Additionally, loading of steel plates by the impinging detonation products was captured by \\ high-speed video recordings. This experimental program has produced results which can be used to \\ calibrate numerical models and to refine the simplified models for predicting blast loads and response of \\ structural elements due to close-in detonations. The effectiveness of polyurea coating for enhancing \\ blast protection of steel plated structures is discussed. The engineering-level model for predicting the \\ blast impact impulse of the detonation gases from the charges in close proximity from the target is \\ introduced and validated using the experimental results obtained during the course of the explosive trials.

\section{Disciplines} \\ Engineering | Science and Technology Studies

\section{Publication Details} \\ Remennikov, A., Ngo, T., Mohotti, D., Uy, B. \& Netherton, M. (2017). Experimental investigation and \\ simplified modeling of response of steel plates subjected to close-in blast loading from spherical liquid \\ explosive charges. International Journal of Impact Engineering, 101 78-89.
}




\section{EXPERIMENTAL INVESTIGATION AND SIMPLIFIED MODELING OF RESPONSE OF STEEL PLATES SUBJECTED TO CLOSE-IN BLAST LOADING FROM SPHERICAL LIQUID EXPLOSIVE CHARGES}

\section{Abstract}

Detonations of nitromethane spherical charges have been carried out to study close-in blast loading of steel plates and the effectiveness of several protective solutions. Three types of bare steel plates, namely mild steel, high-strength steel, and stainless steel were subjected to explosive blast loading. Steel plates of the same type with polyurea coating and composite covers were also subjected to localized blast loading. During an explosive field trial, the blast pressures and displacements of steel plates were measured. Additionally, loading of steel plates by the impinging detonation products was captured by high-speed video recordings. This experimental program has produced results which can be used to calibrate numerical models and to refine the simplified models for predicting blast loads and response of structural elements due to close-in detonations. The effectiveness of polyurea coating for enhancing blast protection of steel plated structures is discussed. The engineering-level 
34 model for predicting the blast impact impulse of the detonation gases from the charges in

35 close proximity from the target is introduced and validated using the experimental results

36 obtained during the course of the explosive trials.

37 Keywords: Impulsive loading; Near-field blast; Protective design; Liquid explosive.

\section{Introduction}

Blast induced effects can be broadly classified into two distinct categories, namely "near field detonation" and "far-field detonations". Due to the portability of small charges within a constrained container such as a back pack or a parcel and likelihood of reaching near to the targets, close-in detonations has become a major treat to the structures and personnel. focus within the research community. The near-field region is defined here as the region within 15-20 radii (for an equivalent spherical blast source) of the face of the explosive with which the blast loading is affected by local phenomena such as the expansion of the detonation products and after burn. These phenomena are not observed in the far field blast loading regime. Therefore, the mechanism of near-field detonation and blast loading is more complex than that of far-field blast loading. concrete filled hollow steel tubes reported the failure mechanism and possible pressure regime development during a near field detonation event. Ngo et al. [1] has identified two 

steel beams. Localized damage has dominated the initial phase of the deformation while global deformation occurred afterwards. It has also emphasized that if the structural element can sustain this initial impulse, it can survive the possible damages caused by the detonation. Remennikov and Uy [2] presented the experimental results of explosive tests conducted on hollow and concrete filled tubular columns. They also demonstrated the effectiveness of the simplified engineering-level models for predicting the response of steel tubular elements to a near-field blast impulse. It was observed that the columns failed due to localized damage caused by the detonation rather than global deformation. Besides, several other researchers have reported the possible consequences due to close-in detonation on structural elements [3-4]. Above mentioned recent studies highlight the importance of further research into the close-in detonation effects by focusing on possible damage mitigation measures. Polyurea has been widely investigated as a suitable material in blast and impact mitigation. Raman et al. [5] conducted a study on the applicability of concrete-polyurea composite as a retrofitting material for concrete structures against blast loads. Three different charge weights $(0.1,0.5$ and $5 \mathrm{~kg})$ of ammonite explosives were used at different stand-off distances. Both polyurea coated and uncoated concrete panels were used in the test program.

71 Crack propagation, out-of-plane deformation, and failure patterns of the panels were investigated and reported. Further, a numerical investigation was carried out using the 
74 that polyurea coating positively contributed to the resistance of structural elements against

75 blast pressure. Ackland et al. [6] reported an experimental and numerical investigation

76 performed on steel-polyurea composite plates subjected to blast loads. However, the results

77 reported in this work have shown a negative influence of polyurea coating on deformation of

78 the steel plates. The bare plates performed better in terms of out-of-plane deformation than

79 the polyurea-steel composite plates. When the polyurea thickness increased, the deformation

80 also increased under the same blast load. The reason for ineffective performance of polyurea

81 coating has been identified as the debonding of the coating from the metal layer during the

82 blast event. This can be considered as the only experimental and numerical investigation that

83 has reported a negative outcome of the application of polyurea. In addition, authors have

84 effectively used polyurea coating as an effective mechanism to mitigate impact loads [7-8].

85 This material has shown a great potential as an impact and blast mitigating component of the

86 protective structures. This experimental program aims to consolidate the authors' previous

87 experiences with using polyurea coating in blast and impact applications and improve the

88 effectiveness of polyurea coating for steel plated structures subjected to close-in blast loads.

89 This study investigates the behavior of steel plate structures with three different steel

90 types under close-in blast loading conditions while focusing on potential damage mitigation

91 techniques through additional polyurea protective coatings. It also focuses on presenting an

92 engineering-level analytical models in predicting the damage caused by close-in blast loading.

93 This work further validates the analytical model for predicting the close-in detonation blast 
94 impulse, which has previously been applied and validated by the authors for the response of

95 steel tubular columns [2]. Once validated through experimental and numerical studies, the proposed blast impulse model can be effectively used for predicting blast induced damage for

97 a wide range of structural components.

\section{Experimental Setup}

\subsection{Test rig}

The test rig for explosive loading of steel plates is shown in Fig.1(a). The test rig was manufactured from welded steel plates with thicknesses of $16 \mathrm{~mm}$ and $25 \mathrm{~mm}$. The overall dimensions of the rig are $1000 \mathrm{~mm} \times 1000 \mathrm{~mm}$ x $800 \mathrm{~mm}$. The steel plate specimens were placed on the top surface of the rig and clamped using the steel flange and twenty seven M24 high-strength bolts. The effective surface area of the plate exposed to the blast source is 700 $\mathrm{mm} \times 700 \mathrm{~mm}$ as shown in Figure 1(b). The test rig was supported by three rectangular

107 hollow sections at the bottom and placed on leveled and compacted soil foundation. The total mass of the rig was nearly $500 \mathrm{~kg}$ which provided sufficient inertia to the rig to prevent excessive movements during close-range detonations of the explosive charges. Plates coated

110 with polyurea on both front and rear surfaces were used in the test program. Two different

111 coating thickness ( $6 \mathrm{~mm}$ and $12 \mathrm{~mm}$ ) were used in order to observe the effectiveness of the

112 coating thickness. Figure 1(c) shows as test setup used with a polyurea coating on the front 113 surface. 
114 Figure 1(d) depicts expanding detonation products and initial stages of formation of the shock

115 wave in the blast tests presented in this paper.

116

117

118

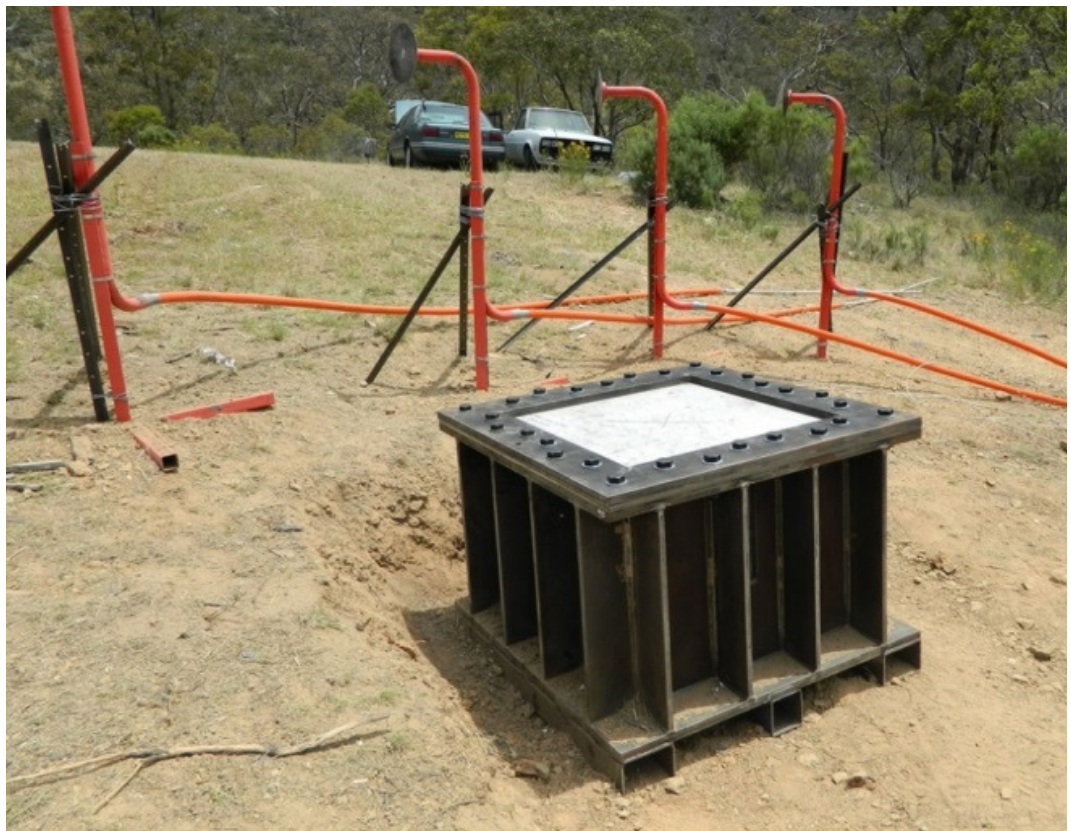

(a)

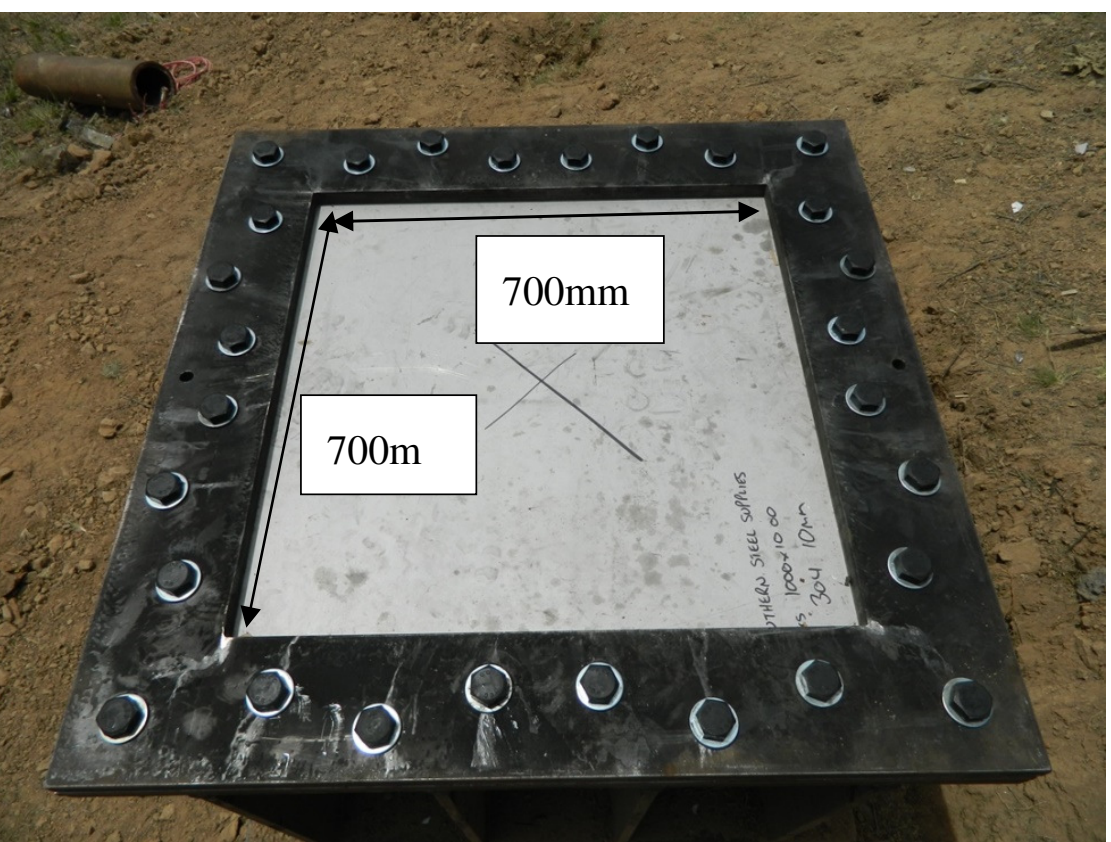

(b) 


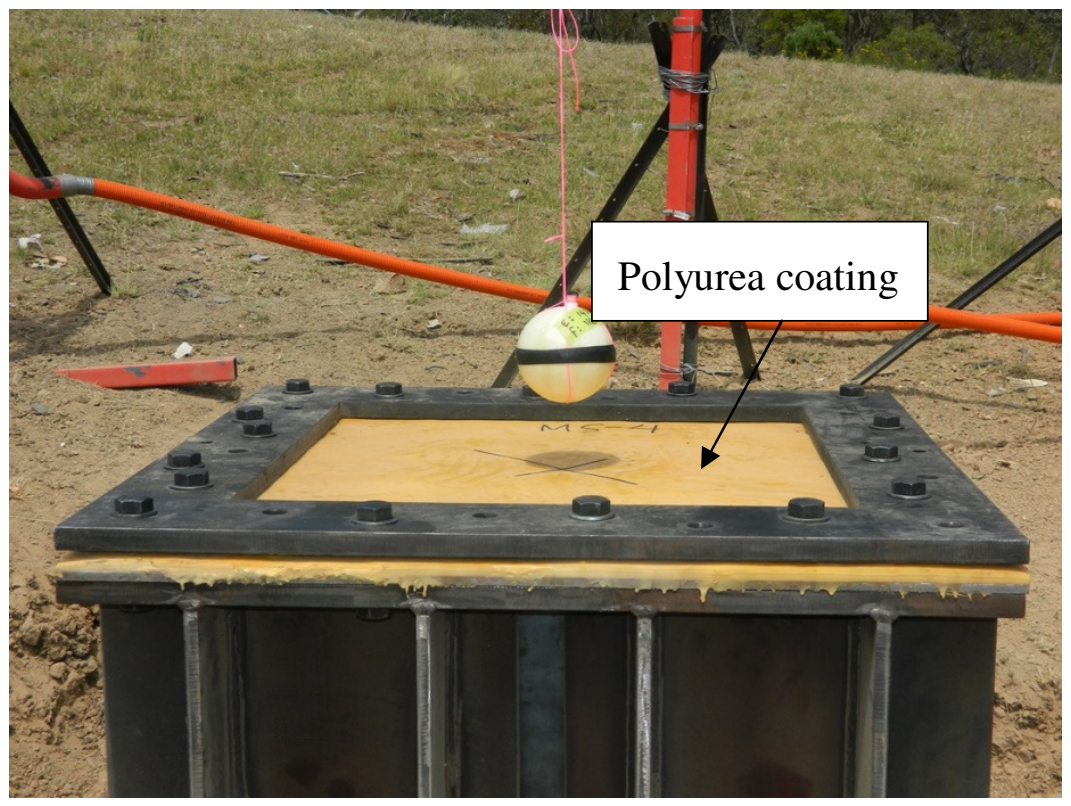

(c)

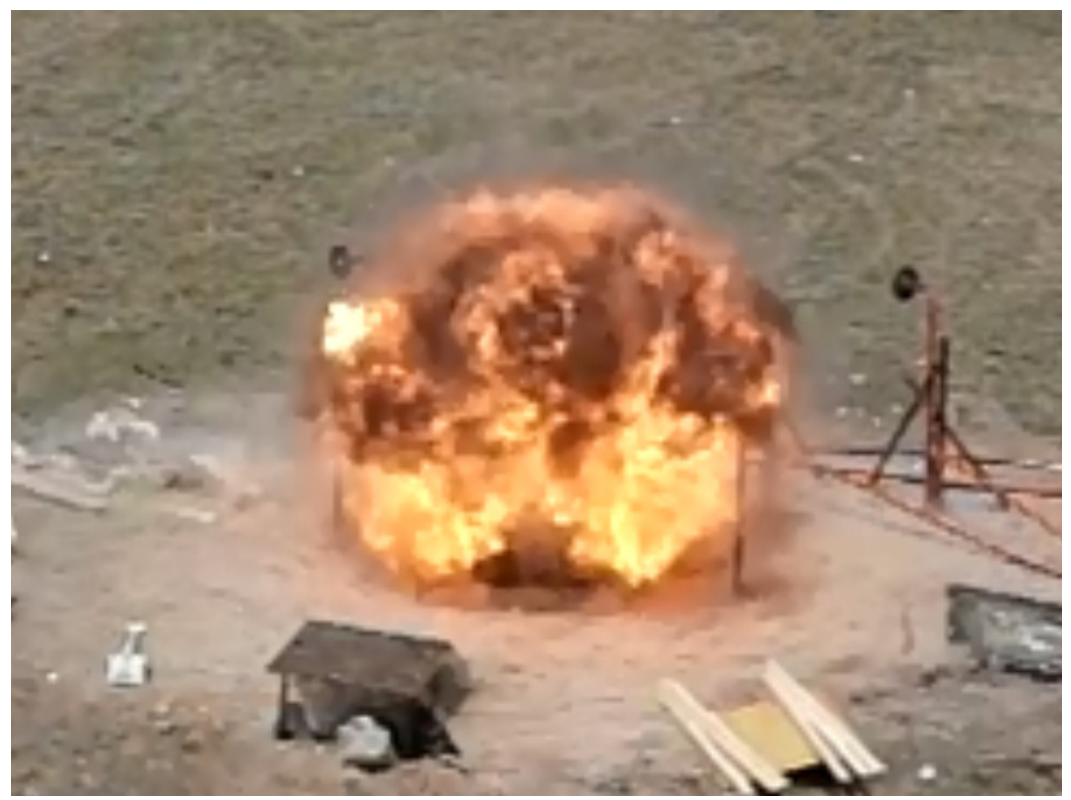

(d)

128 Figure 1: (a) Test rig for explosive loading of steel plates; (b) plate dimensions (c) test setup with the polyurea coated plate (pilot test) (d) fireball and air-blast shock wave. 
132

133 The aim of the testing program was to generate blast loading on the steel plates from $1 \mathrm{~kg}$

134 NEQ TNT spherical charges with central detonation. Manufacturing of perfectly spherical

135 charges from TNT or other solid explosives is not a trivial task. To overcome difficulties with

136 manufacturing spherical charges, it was suggested [10] to use sensitized Nitromethane (NM)

137 as the high explosive material considering that its TNT equivalency is 1.0 as given in [11].

138 The non-fragmenting plastic spherical casings with a diameter of $120 \mathrm{~mm}$ and thickness of

$1391 \mathrm{~mm}$ were manufactured from nylon using 3-D printing technology (Figures 2(a) and (b)).

140 Nitromethane is considered as a liquid explosive. Nitromethane is relatively insensitive

141 and must be initiated by a strong ignition source. The shock front produced by Nitromethane

142 is well formed and produces blast loads with approximately 100\% TNT equivalency [11].

143 The plastic spherical casings were manufactured with a detonator well for inserting and

144 positioning centrally the electric detonators.

145

146 the tests. A series of tests was carried out with a spherical charge supported by a cardboard

147 tube cut to the required length as can be seen in Figure 2(a). This arrangement presented a

148 significant 'shock focusing effect' which will be discussed later. Another series of tests was

149 performed by suspending the charges from steel cables using nylon strings as shown in Figure 150 2(b).

151 


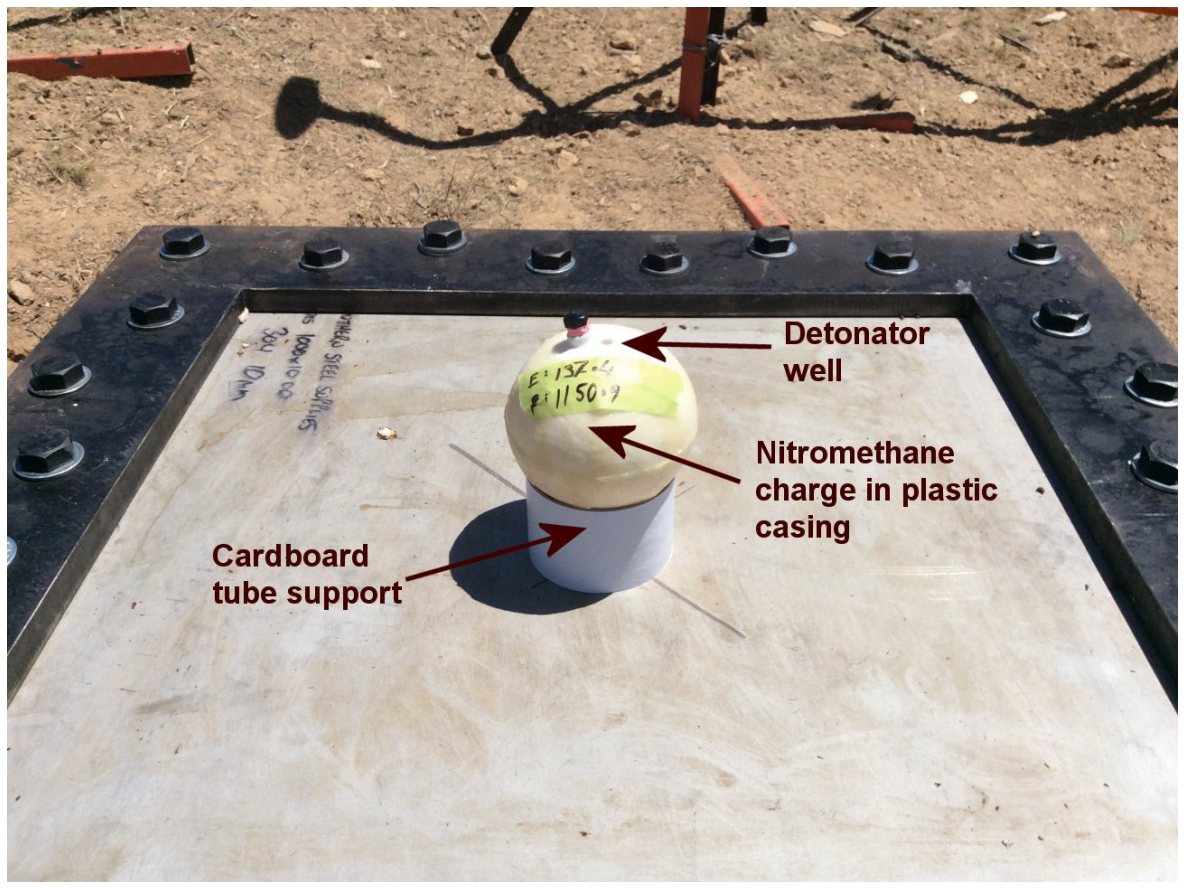

(a)

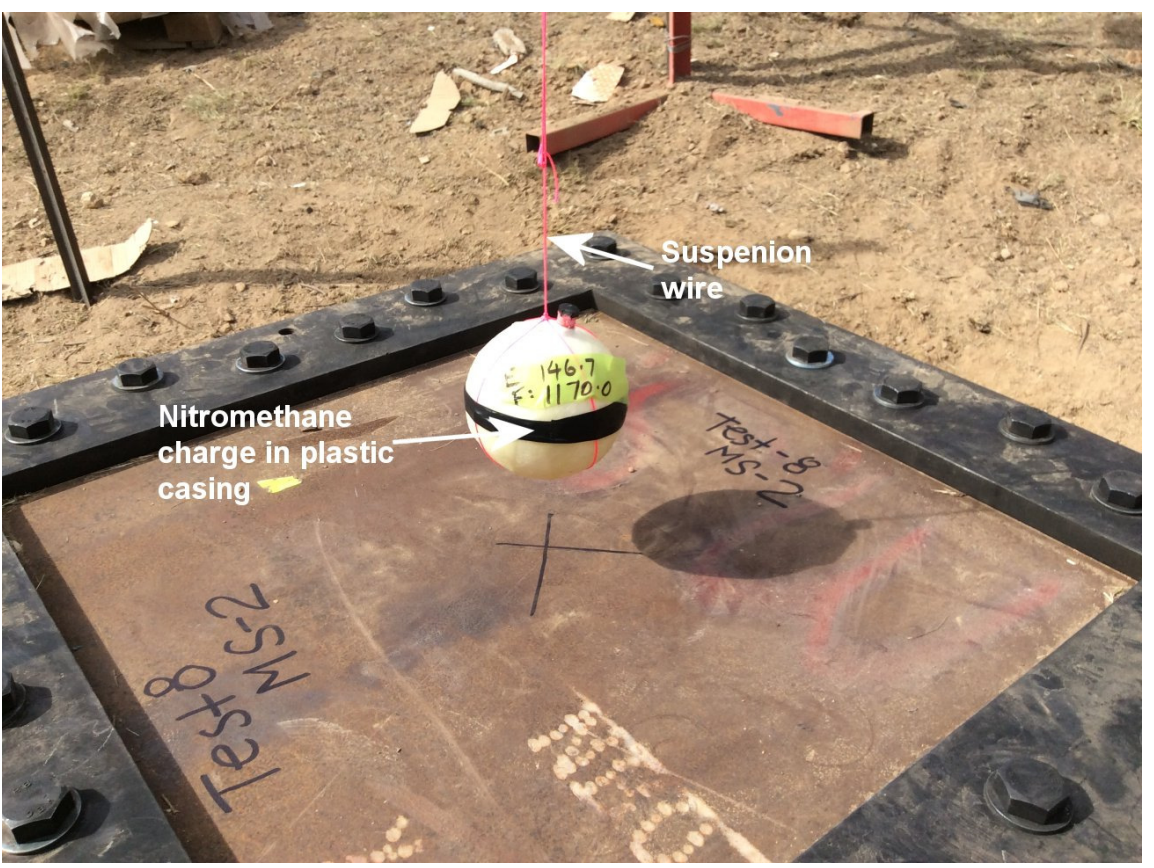

(b)

156 Figure 2: Nitromethane spherical charges: (a) supported by cardboard tube; (b) suspended with strings.

\subsection{Steel plate specimens}

159 All steel plate specimens had dimensions $1000 \mathrm{~mm} \times 1000 \mathrm{~mm}$ and $10 \mathrm{~mm}$ thickness. The 
160 thickness of the plates was chosen based on the results of pre-test numerical simulations so

161 that to avoid rupture failure of the test plates.

The experimental program included three types of steel plates to compare their

163 performance under near-field blast loading. Bluescope XLERPLATE Grade 350 steel was

164 chosen as the baseline material due to its widespread availability and for comparison with the

165 previous blast test results [3]. High-strength steel BISPLATE 80 from Bisalloy Steel Group

166 Limited was selected due to its potential applications in protective structures. Grade 304

167 austenitic stainless steel was selected due to its excellent ductility and energy absorption

168 which makes this steel a good candidate for use in security and protective structures

169 applications. Table 1 summarizes the typical mechanical properties of the steels used in the

170 trial. Figure 3 provides the engineering stress-strain diagrams for XLERPLATE 350 and

171 BISPLATE 80 steels obtained by tensile testing of the standard steel specimens using the

172 universal testing machine Instron under quasi-static loading rate. Note that a full stress-strain

173 diagram for the stainless steel was not available at the time of preparing the paper.

174

175 Table 1: Typical mechanical properties of steel plates used in explosive trial

\begin{tabular}{c|c|c|c}
\hline Steel/Grade & $\begin{array}{c}\text { Tensile Strength } \\
(\mathbf{M P a})\end{array}$ & $\begin{array}{c}\text { Yield Strength } \\
\mathbf{0 . 2 \%} \text { Proof (MPa) }\end{array}$ & $\begin{array}{c}\text { Uniform Elongation } \\
(\boldsymbol{\%})\end{array}$ \\
\hline $\begin{array}{c}\text { Bluescope 350 } \\
\text { XLERPLATE }\end{array}$ & 480 & 356 & 30 \\
\hline Bisalloy BISPLATE 80 & 773 & 715 & 8 \\
\hline 304 Stainless Steel & - & 325 & - \\
\hline
\end{tabular}

176 


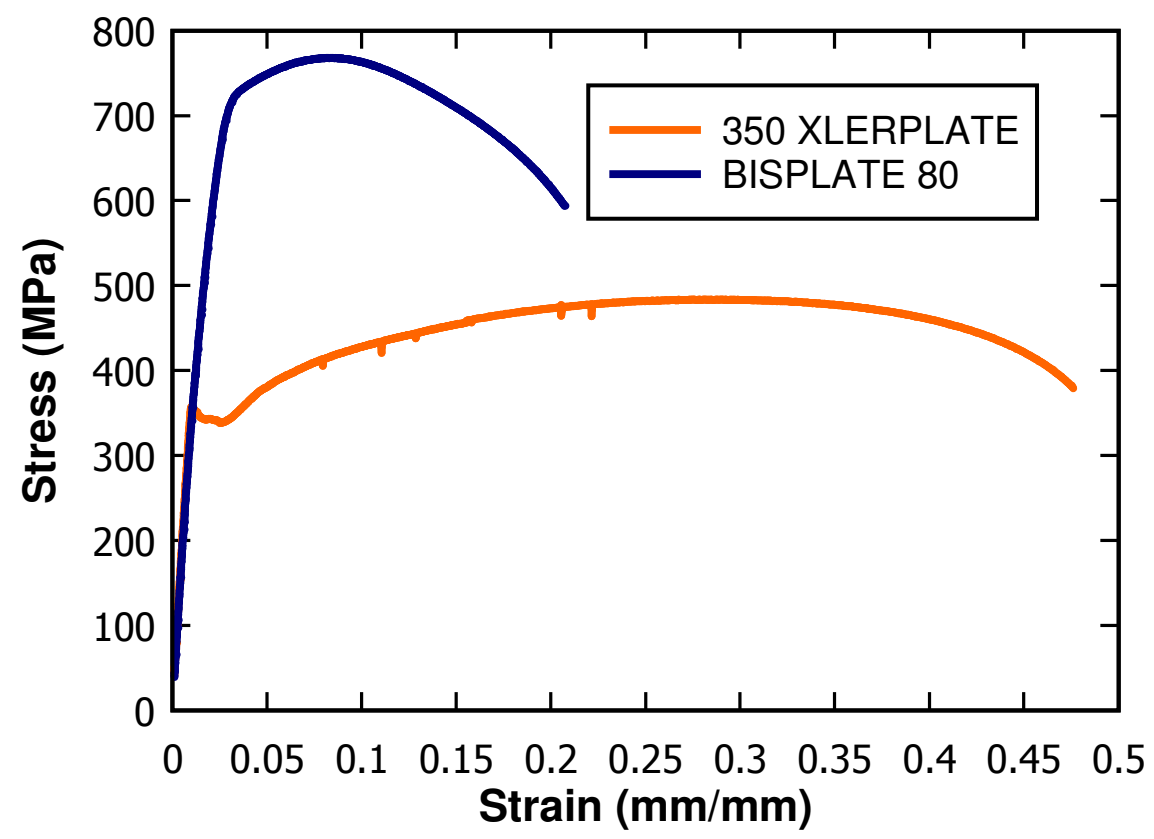

177

178

179

180

181

182 Polyurea used in this study was Eraspray ESU630D ${ }^{\circledR}$, supplied by Era Polymers Pty Ltd.,

183 Australia. High strain rate tensile tests on the polyurea sample were conducted in order to

184 obtain the stress-strain properties of the material at different strain rates. A comprehensive

185 study on the high strain rate behaviour of Eraspray ESU630D ${ }^{\circledR}$ at high strain rates has been

186 reported in Mohotti et al. [7]. In addition, authors have effectively used polyurea-aluminium

187 plate system in reducing the damage caused by low and high speed projectiles [8]. The

188 well-established Mooney-Rivlin material model has shown reasonably good representation

189 of the stress-strain behaviour of the material under individual strain rates. Therefore,

190 Mooney-Rivlin material model was used in the finite element model to represent the 
191 stress-strain behaviour of polyurea. True stress-strain behaviour of the polyurea used in this 192 test program is presented in Figure 4.

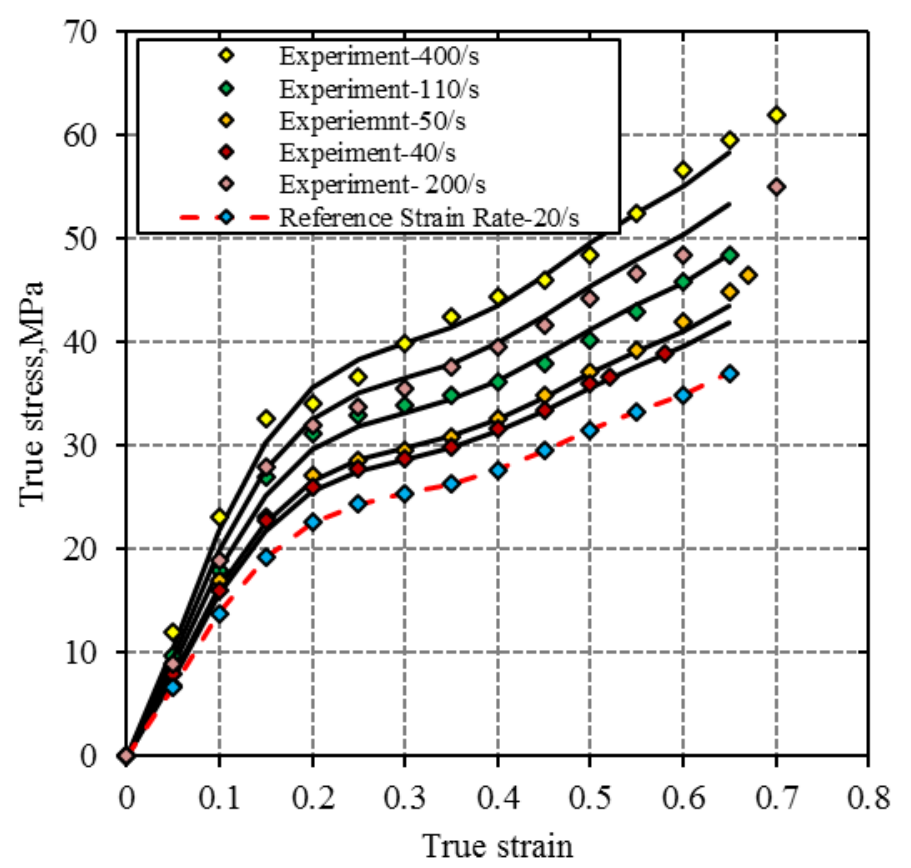

193

Figure 4: Stress-strain relationships for polyurea [7].

195

196

197

198

199

\subsection{Instrumentation}

Blast pressure time histories were recorded making use of a blast data recording system developed by the University of Newcastle (UoN). Netherton et al. [12] describes the system's components, which are summarised as:

- A sensor sub-system that includes piezoelectric gauges (PCB Model 113A), gauge support discs, and instrumentation support frames.

- A data collection sub-system that includes an integrated electronic piezoelectric excitation power supply unit and a 24-channel, $2 \mathrm{MHz}$ data acquisition and storage unit. 
of a mechanical comb-like device that was similar to the device described by Neuberger et al.

[13]. The teeth of the comb possess a gradually decreasing height as depicted in Figure 5(a).

207 When positioned under the dynamically deflecting plate, the long teeth are permanently bent 208 while those that are shorter than the maximum deflection remain intact. Figure 5(b) shows deformed mechanical gauges for HS-1 and SS-1 test configurations.

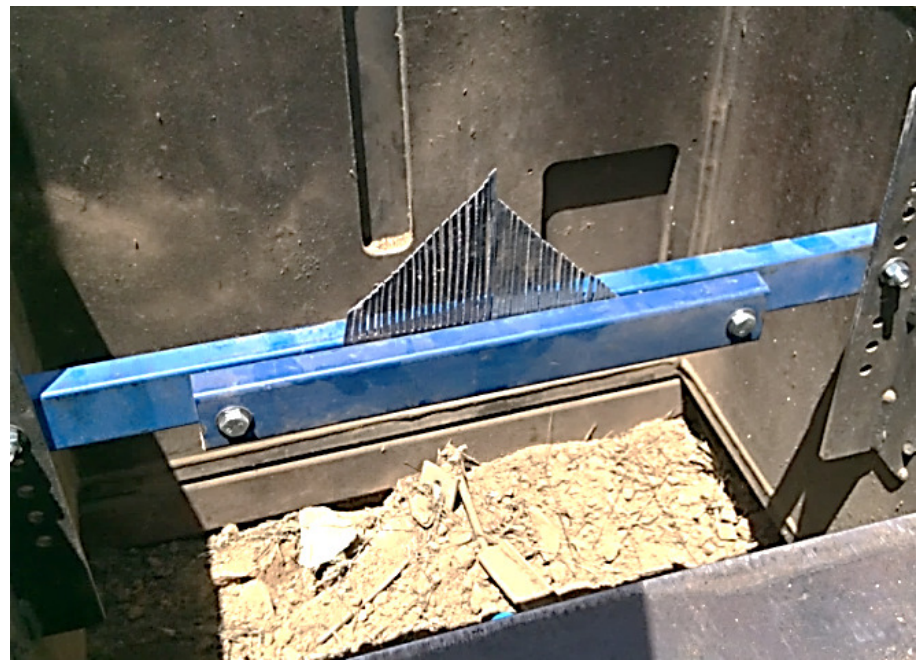

(a)

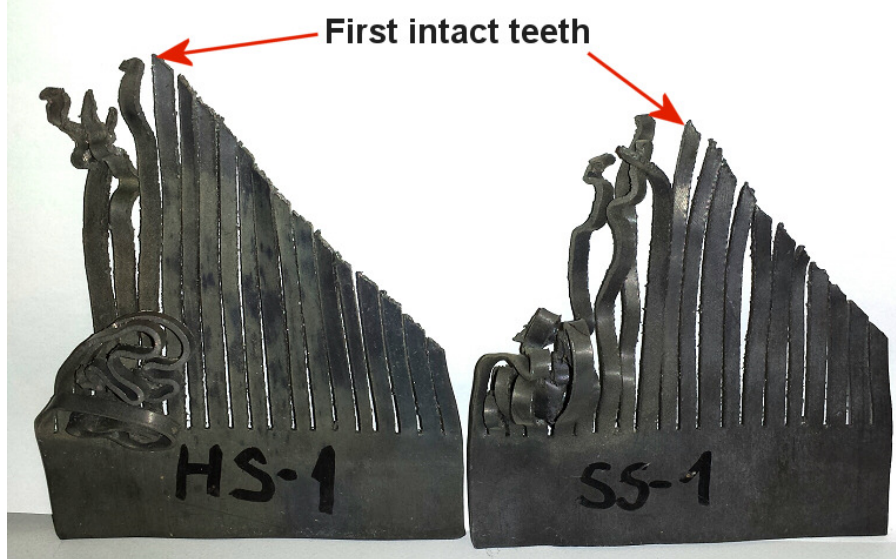

(b)

213 Figure 5: Mechanical gauge for measuring peak deformation of plates: (a) installation in the test rig; (b) samples of deformed gauges for HS-1 and SS-1. 


\subsection{Experimental program}

217 The experimental program consisted of nine test configurations. Bare steel plates were used

218 as a reference for the coated plate configurations. Three groups of steel plates MS, HS and SS

219 were used in the test program and each specimen was designated according to its number in

220 the steel type group (e.g. SS-1, HS-1, MS-1) as shown in Table 2. These configurations were

221 used to compare the performance of each grade of steel subjected to the same amount of

222 explosive energy from the charges placed at the stand-off distances of $110 \mathrm{~mm}$ and $150 \mathrm{~mm}$.

223 Test configuration 5 (MS-2) was used as the reference for the configurations 6 (MS-3)

224 and 7 (MS-4) where the polyurea coating was applied on the top surface of the mild steel

225 plates. For the test configurations 5-9, the standoff distance was fixed as $150 \mathrm{~mm}$. Several

226 studies have been conducted to find out the effectiveness of polyurea coating when it is

227 applied to the surface opposite to the blast source or the surface facing the blast source $[5,6]$.

228 However, no clear comparative evidence has been reported in order to reach a conclusion on

229 the effectiveness of the polyurea coating as a front or back side protective shield. Therefore,

230 in this study polyurea coating was used as both front and back side protective shield. In

231 configurations 6 and 7, mild steel plates were sprayed with $6 \mathrm{~mm}$ and $12 \mathrm{~mm}$ thick polyurea

232 coating as a front side protective shield.

233 BISPLATE 80 plates were used in configurations 8 (HS-3) and 9 (HS-4) with 6 mm and

$23412 \mathrm{~mm}$ thick polyurea coatings. In configuration 9, BISPLATE 80 plate was sprayed with 12

235 mm thick polyurea coating at the back side of the plate. Those were used for the comparison 
236 with the coated mild steel plates with the similar coating arrangements.

237 Table 2: Description of test configurations

\begin{tabular}{|c|c|c|c|c|}
\hline $\begin{array}{c}\text { Test } \\
\text { configurations }\end{array}$ & $\begin{array}{l}\text { Steel plate } \\
\text { material }\end{array}$ & $\begin{array}{c}\text { Protective } \\
\text { polyurea coating }\end{array}$ & $\begin{array}{c}\text { Charge } \\
\text { support/suspension }\end{array}$ & $\begin{array}{l}\text { Stand-off distance, } \\
\mathrm{mm}\end{array}$ \\
\hline 1 (SS-1) & SS Grade 304 & - & $\begin{array}{l}\text { Cardboard tube } \\
\text { support }\end{array}$ & $110 \mathrm{~mm}$ \\
\hline $2(\mathrm{HS}-1)$ & $\begin{array}{c}\text { BISPLATE } \\
80\end{array}$ & - & $\begin{array}{c}\text { Cardboard tube } \\
\text { support }\end{array}$ & $110 \mathrm{~mm}$ \\
\hline 3 (HS-2) & $\begin{array}{c}\text { BISPLATE } \\
80\end{array}$ & - & Suspension & $110 \mathrm{~mm}$ \\
\hline $4(\mathrm{MS}-1)$ & $\begin{array}{c}\text { XLERPLATE } \\
350\end{array}$ & - & Suspension & $110 \mathrm{~mm}$ \\
\hline 5 (MS-2) & $\begin{array}{c}\text { XLERPLATE } \\
350\end{array}$ & - & Suspension & $150 \mathrm{~mm}$ \\
\hline $6(\mathrm{MS}-3)$ & $\begin{array}{c}\text { XLERPLATE } \\
350 \\
\end{array}$ & 6mm (top) & Suspension & $150 \mathrm{~mm}$ \\
\hline 7 (MS-4) & $\begin{array}{c}\text { XLERPLATE } \\
350\end{array}$ & $12 \mathrm{~mm}$ (top) & Suspension & $150 \mathrm{~mm}$ \\
\hline 8 (HS-3) & $\begin{array}{c}\text { BISPLATE } \\
80\end{array}$ & $6 \mathrm{~mm}$ (top) & Suspension & $150 \mathrm{~mm}$ \\
\hline 9 (HS-4) & $\begin{array}{c}\text { BISPLATE } \\
80\end{array}$ & $12 \mathrm{~mm}$ (bottom) & Suspension & $150 \mathrm{~mm}$ \\
\hline
\end{tabular}

\section{Analysis of experimental results}

\subsection{Response of bare steel plates to close-range suspended charges}

241 Responses of bare steel plates used in the test configurations were assessed based on their

242 permanent (residual) plastic deformation. Table 3 demonstrates the deformation profiles of

243 the bare steel plates after being subjected to close-range detonation of the $1 \mathrm{~kg} \mathrm{NM}$ charges

244 suspended over the center of the plates at the standoff distances $110 \mathrm{~mm}$ and $150 \mathrm{~mm}$. In order

245 to determine the plate deformed profiles and the residual deformations, a 3-D scanning

246 system was used. The 3-D scanned images of the deformed steel plates are included in Table 3. 
247 Using the specialized software Geomagic Qualify, the scanned images of the steel plates were

248 digitally processed and the deformation profiles and the peak residual deformations at the

249 center of the plates were determined. The peak residual deformations are summarized in

250 Table 3 and will be used in the subsequent sections for validating the analytical and numerical

251 models of plate response to close-range blast impulses.

253 Table 3. Experimental results for bare steel plate specimens (suspended charges)

\begin{tabular}{|c|c|c|c|}
\hline $\begin{array}{c}\text { Test \# } \\
\text { Plate Material }\end{array}$ & $\begin{array}{l}\text { 3D scanned view of deformed } \\
\text { plates }\end{array}$ & Deformed plate profile & $\begin{array}{l}\text { Residual } \\
\text { deformat } \\
\text { ion }(\mathrm{mm})\end{array}$ \\
\hline $\begin{array}{c}\text { MS-1 } \\
\text { XLERPLATE } \\
350\end{array}$ & $\begin{array}{lll}\because & \cdots & \cdots \\
\vdots & & \vdots\end{array}$ & & 102 \\
\hline $\begin{array}{c}\text { MS-2 } \\
\text { XLERPLATE } \\
350\end{array}$ & $\therefore$ & 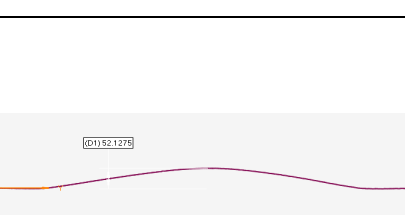 & 64.0 \\
\hline $\begin{array}{c}\text { HS-2 } \\
\text { BISPLATE } \\
80\end{array}$ & $\therefore . .$. & 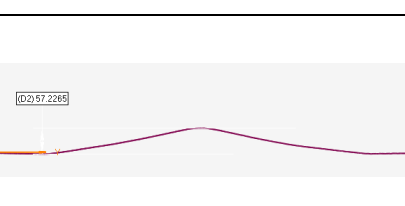 & 57.6 \\
\hline
\end{tabular}

255 Analysis of the results in Table 3 demonstrates that the performance of high strength steel

256 plate HS-2 was superior to the mild steel plate MS-2 in resisting the near-field blast loading

257 from a $1 \mathrm{~kg}$ NM charge at the standoff distance $110 \mathrm{~mm}$ (scaled standoff distance 0.11

$258 \mathrm{~m} / \mathrm{kg}^{1 / 3}$ ). The residual deformation was reduced by about $43 \%$ by replacing the steel with a

259 characteristic yield stress of $350 \mathrm{MPa}$ with the high strength steel with a characteristic $0.2 \%$

260 proof stress of $690 \mathrm{MPa}$. 
262 mild steel plates MS-1 and MS-2 where the variable parameter was the standoff distance. It

263 shows that even small change in the standoff distance from $110 \mathrm{~mm}$ to $150 \mathrm{~mm}$ (scaled

264 standoff distances from $0.11 \mathrm{~m} / \mathrm{kg}^{1 / 3}$ to $0.15 \mathrm{~m} / \mathrm{kg}^{1 / 3}$ ) in the close-in detonations could

265 produce significant damage mitigation by reducing the plate residual deformation by nearly

$26640 \%$.

\subsection{Response of steel plates with polyurea coating}

268 The effectiveness of the polyurea coating was assessed by comparing the residual

269 deformations of the bare steel plates MS-2 and HS-2 with the coated steel plates. The standoff

270 distance was selected as $150 \mathrm{~mm}$ to ensure that no major fracture failures occurred in the steel

271 plates after the detonation. Polyurea has a relatively low melting temperature of $270^{\circ} \mathrm{C}$. After

272 burn will result in high temperature in the steel plate which, in turn, will soften the steel plate

273 and melting the polyurea layer as shown in Figure 6. This makes polyurea layer less effective

274 when it applied on the front face of the plate which faces the blast source.
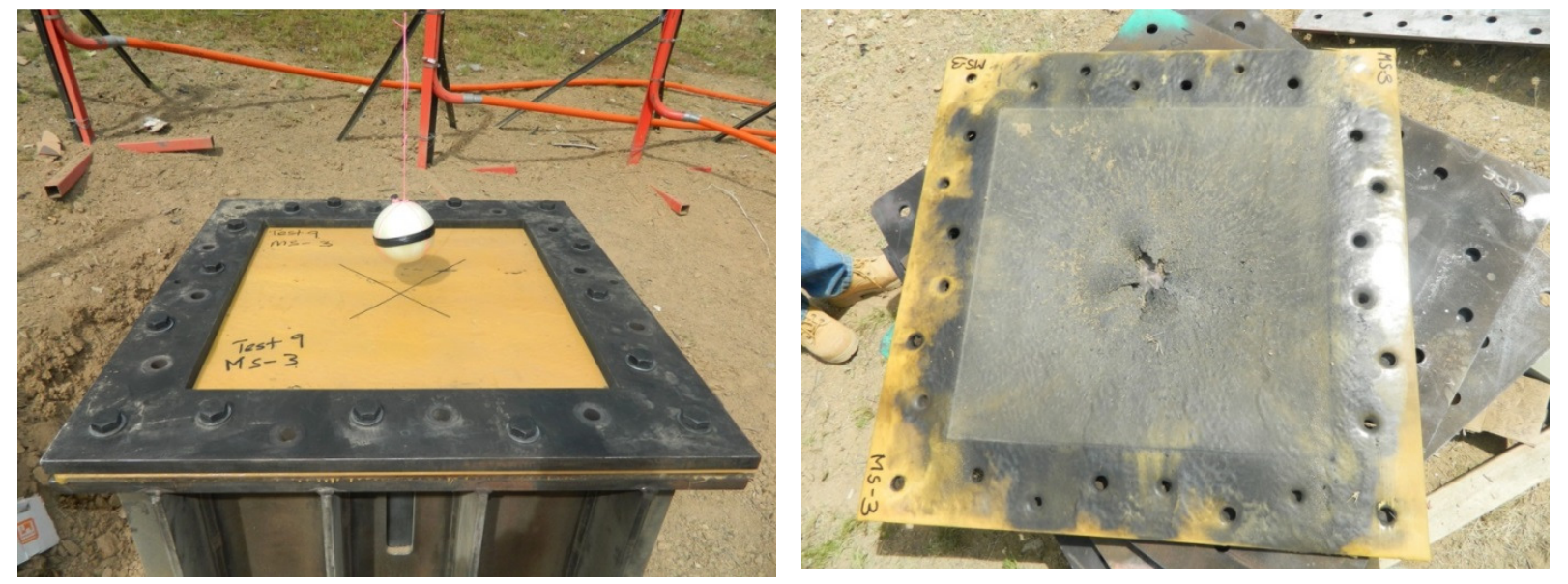

275 Figure 6: Melting of polyurea layer when applied on the front $t$ surface facing the blast source. 
coatings, respectively, applied to the surface facing the charge. The peak residual deformation

produced by MS-3 plate was $55.6 \mathrm{~mm}$, and the peak residual deformation of MS-4 plate was

be observed that both configurations MS-3 and MS-4 with the polyurea coating on the front

face of the plate delivered only modest reductions between 13 and 18 percent to the plate

282 damage compared to the bare plate configuration MS-2.

Figure 7 shows that the most effective approach to mitigating damage of the steel plates

284 from the near-field detonations was applying a $12 \mathrm{~mm}$ polyurea coating to the back side of the

285 HS-4 steel plate that was not directly exposed to the flow of gas detonation products. In

286 comparison with the mild steel plate MS-2, it appears that substituting the steel with higher

287 strength steel and applying a $12 \mathrm{~mm}$ polyurea coating to the back side of the plate could

288 produce a reduction of about $62 \%$ in the plate permanent deformation.

290 Table 4. Experimental results for bare steel plate with polyurea coating (suspended charges)

\begin{tabular}{|c|c|c|c|}
\hline $\begin{array}{c}\text { Test \# } \\
\text { Plate material }\end{array}$ & $\begin{array}{c}\text { 3D view of deformed } \\
\text { shape }\end{array}$ & 3D scanned profile & $\begin{array}{c}\text { Residual } \\
\text { deformation } \\
(\mathrm{mm}) \\
(3 \mathrm{D} \\
\text { scanned })\end{array}$ \\
\hline $\begin{array}{c}\text { HS-3 } \\
\text { BISPLATE } \\
80 \\
6 \mathrm{~mm} \\
\text { polyurea } \\
\text { coating (top) }\end{array}$ & & 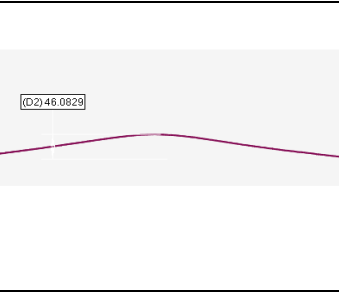 & 45.8 \\
\hline
\end{tabular}



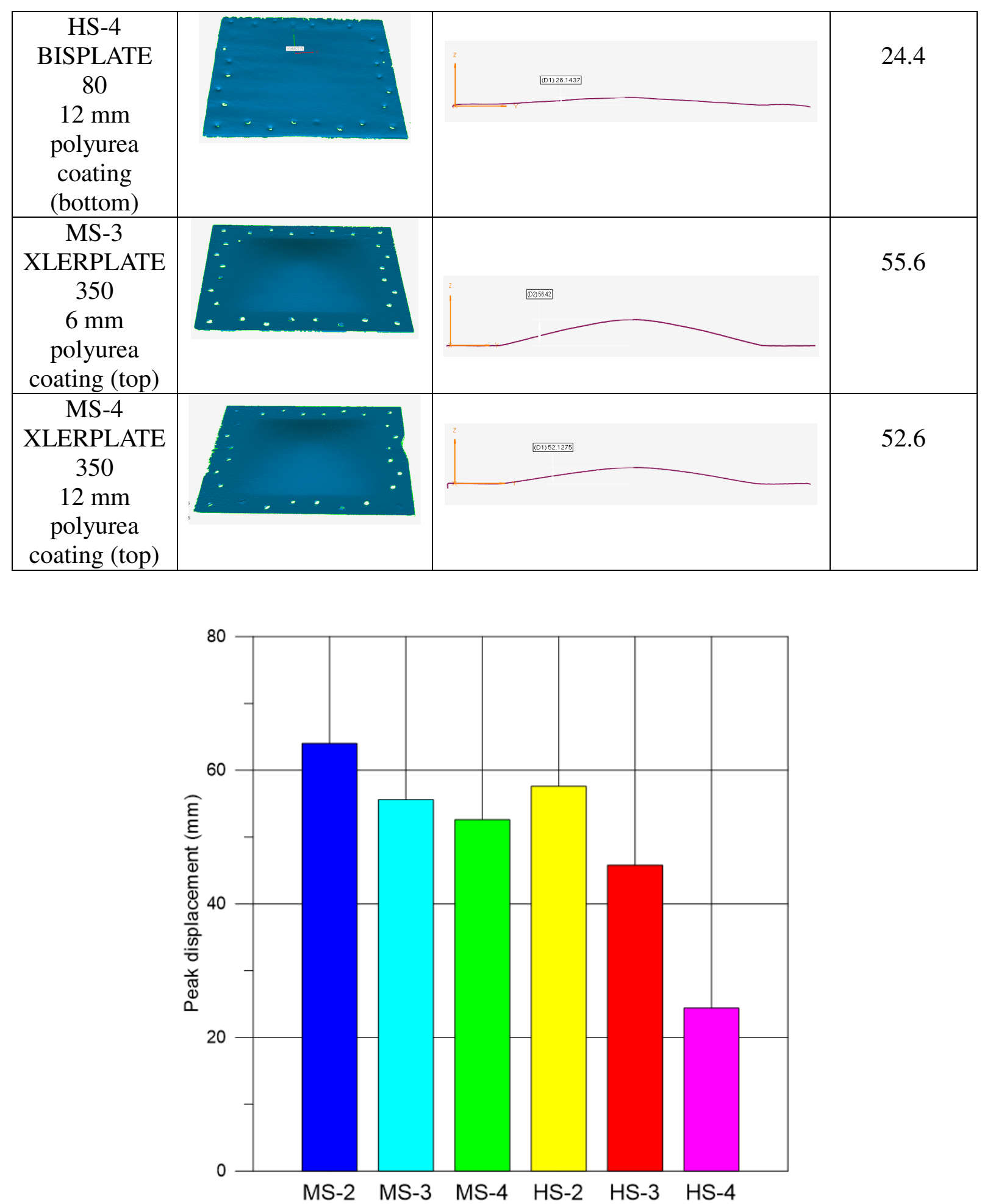

293 Figure 7: Effect of polyurea coating for MS and HS steel plates (MS-2: bare plate, MS-3: 6

$294 \mathrm{~mm}$ polyurea coating facing explosion, MS-4: $12 \mathrm{~mm}$ polyurea coating facing explosion, 295 HS-2: bare plate, HS-3: $6 \mathrm{~mm}$ polyurea coating facing explosion, HS-4: $12 \mathrm{~mm}$ polyurea coating on opposite side from explosion) 


\section{Focusing flow of detonation gases with weak media}

299 As shown in Figure 2(a), the cardboard tube stands were used in several tests to position the

300 spherical NM charges at a standoff distance of $110 \mathrm{~mm}$ above the steel plates. The effect of

301 the cardboard tube stands on the steel plate response is presented in Figure 8. It is evident

302 from Figure 8(a) that the cardboard tube stand acted as a blast focusing device that resulted in

303 the concentrating of blast energy within the tubular stand and penetration of the high-strength

304 steel plate HS1 by the hot detonation gases. The depth of localized penetration was about 5

$305 \mathrm{~mm}$. Figure 8(b) demonstrates the response of the stainless steel plate SS-1 due to detonation

306 of a spherical charge supported by a cardboard tube stand. One can notice the blast focusing

307 effect that resulted in the localized penetration of the plate. Figure 8(c) shows a close-up view

308 of the localized damage of the plate.

309 The experimental results have provided the evidence that blast focusing could be

310 achieved by manufacturing blast focusing devices from such weak media as cardboard.

311 Furthermore, it has been confirmed that tubular cardboard stands are capable of focusing

312 energy of explosion of a spherical charge and force the explosion products out along the axis

313 of the tubular stand. The amplified and concentrated blast energy can be used for

314 transforming the blast flow from spherical explosive charges for penetrating targets in

315 military and civilian applications. 


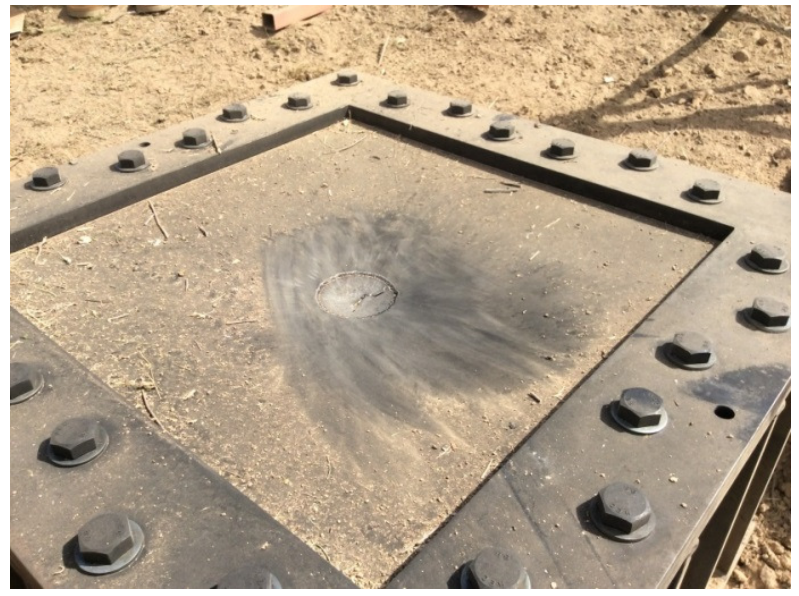

(a)

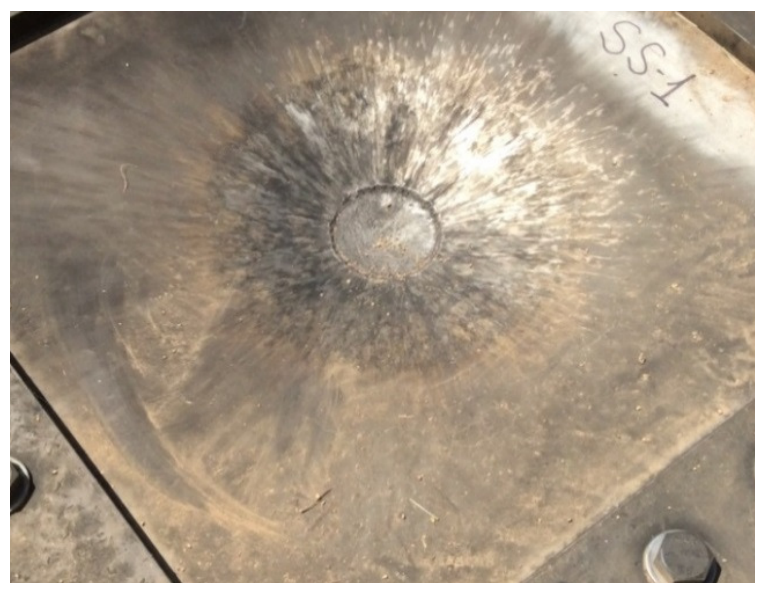

(b)

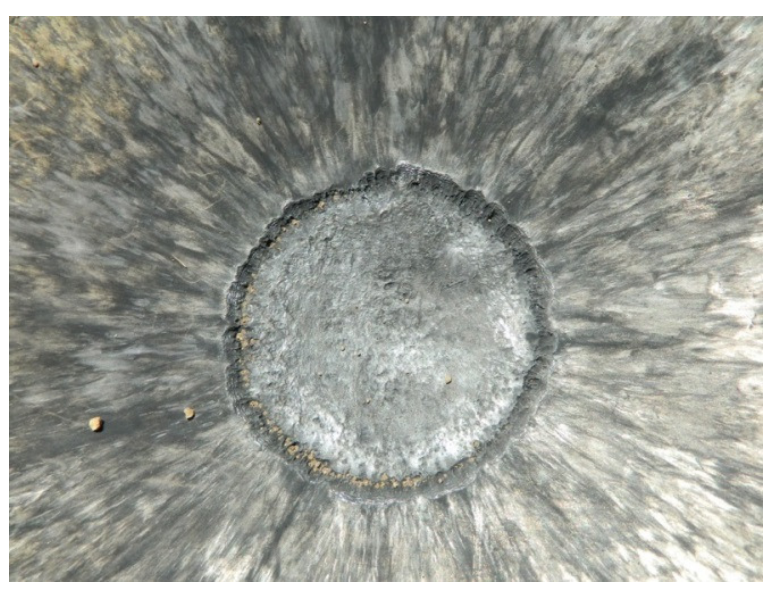

(c)

323 Figure 8: Effect of cardboard stands: (a) response of BISPLATE 80 steel plate HS-1; (b) 324 response of stainless steel Grade 304 plate SS-1; (c) close-up view of plate localized damage. 
327 by the cardboard rings are presented in Table 5. Direct comparison can be made for the steel

328 plates HS-1and HS-2 as in both configurations the standoff distance was $110 \mathrm{~mm}$. It can be

329 noticed that the configuration with the cardboard stand, HS-1, produced damage that is about

$33010 \%$ larger than for the charge centrally suspended over the plate, HS-2, at the same standoff

331 distance, in addition to significant localized damage within the diameter of the cardboard ring

332 support. Table 5 also presents the peak dynamic deflections of the steel plates HS-1 and SS-1

333 determined using the mechanical gauges described in Section 2.5.

334

335 Table 5. Experimental results for bare steel plate (cardboard charge supports)

\begin{tabular}{|c|c|c|c|c|}
\hline $\begin{array}{c}\text { Test \# } \\
\text { Plate } \\
\text { material }\end{array}$ & $\begin{array}{l}\text { 3D view of deformed } \\
\text { shape }\end{array}$ & Deformed plate profile & $\begin{array}{c}\text { Residual } \\
\text { deformation } \\
(\mathrm{mm})\end{array}$ & $\begin{array}{l}\text { Mech. } \\
\text { gauge } \\
(\mathrm{mm})\end{array}$ \\
\hline $\begin{array}{c}\text { HS-1 } \\
\text { BISPLATE } \\
80 \\
\end{array}$ & . $=.=$ & 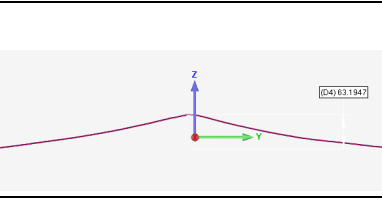 & 65.7 & 73 \\
\hline $\begin{array}{c}\text { SS-1 } \\
\text { Stainless } \\
\text { steel Grade } \\
304 \\
\end{array}$ & $\therefore$. & $\begin{array}{l}108519 \\
\end{array}$ & 85.3 & 93 \\
\hline
\end{tabular}

\section{Analysis of blast pressure records}

338 Multiple pressure-time histories were captured for 17 independent explosive shots, via four

339 blast gauges per shot, each of which were located alongside the test-rig; see Figures 1(a) and

340 1(b). Gauge location \#01 is the furthest to the left within Figure 1(a), with gauge \#2 to the 
341 right of $\# 1$, then $\# 3$ to the right of $\# 2$, whilst \#4 is the furthest right within the image. The

342 intent was not to observe blast pressures on the test-rig itself; rather, the recorded values are

343 useful in terms of calibrating the modelling of blast waves in the vicinity of the actual test-rig,

344 such that NEQ, air temperature and pressure are appropriately considered. The data is also

345 extremely useful in terms of recording spherical free-air bursts from bare Nitromethane and

346 confirming statistical parameters for the NEQ of the explosive compound as used.

347 Figure 9 shows initial stages of the fireball formation and expansion of the gas detonation

348 products (Figure 9(a)) followed by the formation of the shock waves in the air (Figure 9(b))

349 which were recorded by pressure gauges \#1 through 4 . Table 3 presents data from the gauges

350 for shots \#15 through 17 representing three tests involving free air detonation of $1 \mathrm{~kg}$ spherical

351 Nitromethane charges. The charges were suspended from a wire at a height of $2.5 \mathrm{~m}$ above the

352 ground surface. This ensured that the blast wave arrived first at the blast pressure gauges

353 measuring incident blast overpressures without being contaminated by the reflected shocks.
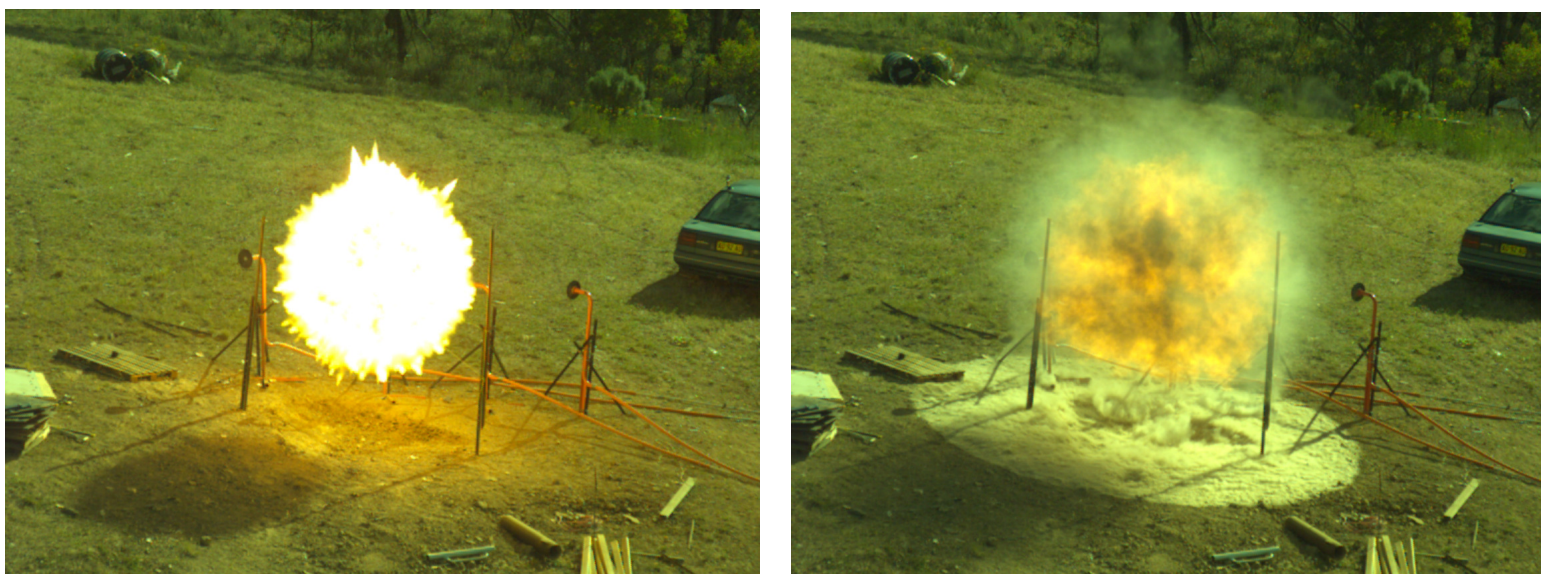

356 Figure 9: Free air detonation of spherical $1 \mathrm{~kg} \mathrm{NM}$ charges: (a) initial spherical expansion of 
Figure 10 shows the experimental trace for shot \#17 as example of pressure-time

361 histories recorded by the incident pressure gauges, with relevant blast parameters - peak

362 pressure, positive and negative phase impulse, arrival time and second shock arrival time -

363 labelled. Some features could be identified from the pressure time history. Firstly, the peak

364 pressure can be clearly identified since the pressure gauges did not show any adverse ringing

365 effects. Secondly, the second shock can be seen to arrive at around $3.5 \mathrm{msec}$ after detonation.

366 This is caused by successive reflection of the shock wave off the air/explosives interface

367 shortly after detonation. It can be noticed that a tertiary shock arrived at around $6.0 \mathrm{~ms}$ after

368 detonation due to reflection of the primary shock off the ground surface, however it can be

369 discounted since it affected only the negative phase part of the blast pressure curve. 


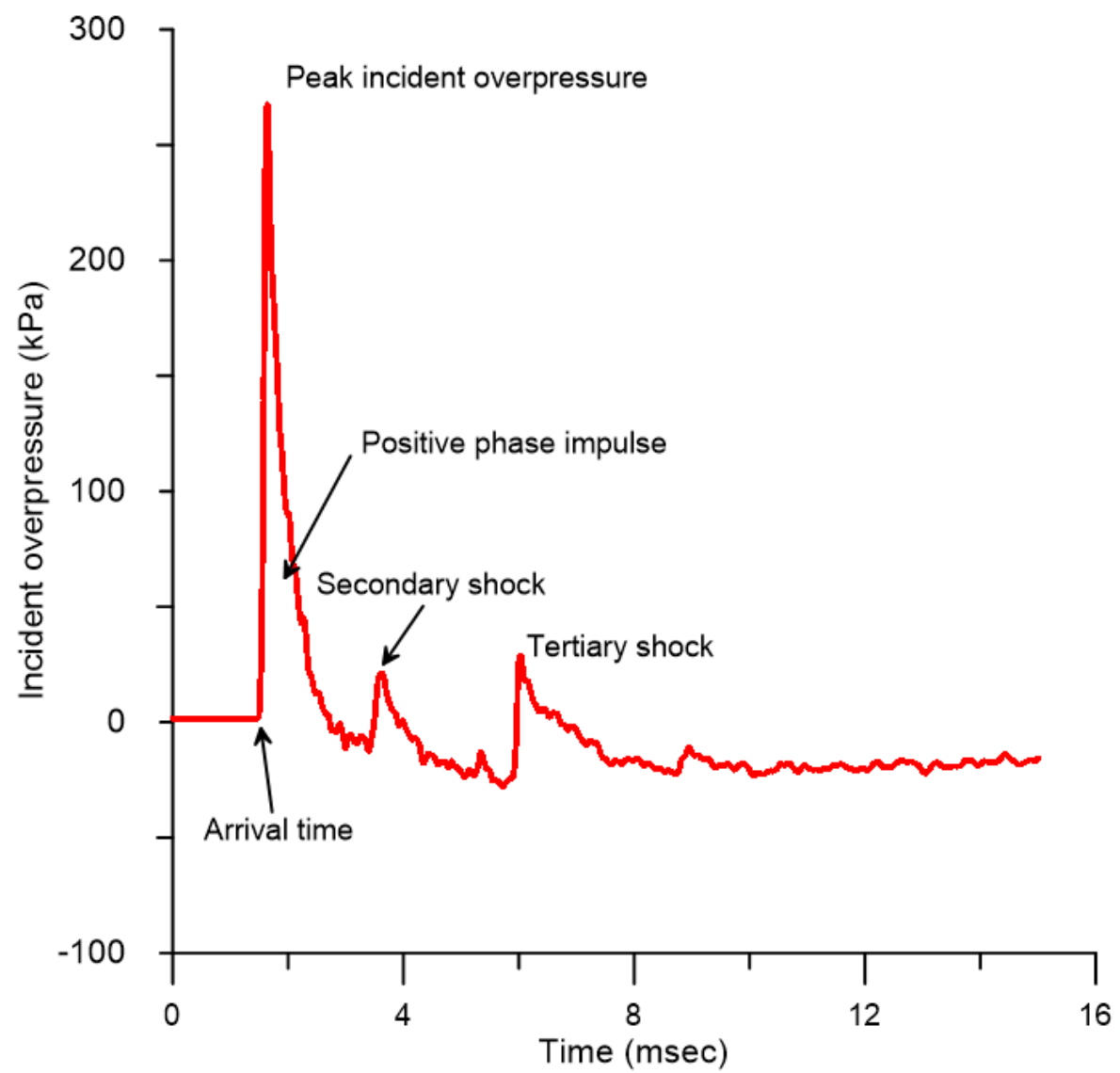

Figure 10: Example of recorded blast pressure-time histories, explosive shot \#17 for gauge

The TNT equivalence of an explosive is given as the equivalent mass of TNT required to produce a blast wave of equal magnitude to that produced by a unit weight of the explosive in

377 question. Currently, there is a lack of information in the literature on the TNT equivalence of

378 Nitromethane. Table 3 also contains the predicted peak incident overpressures and impulses

379 from a $1 \mathrm{~kg}$ TNT spherical charge calculated by the computer program CONWEP which is

380 based on the Kingery-Bulmash model [19]. It can be seen that the experimental incident

381 overpressures exceed with the measured incident overpressures from $1 \mathrm{~kg}$ Nitromethane

382 charges by 12 to 34 percent with an average incident pressure equivalency of 1.26 . TNT 
spherical bursts of the NM charges. An averaged value of pressure and impulse equivalency

can be assumed as 1.13 for spherical Nitromethane charges in far-field blast events.

Table 6. Recorded blast data for free-air bursts of $1 \mathrm{~kg} \mathrm{NM}$.

\begin{tabular}{|c|c|c|c|c|c|c|c|c|}
\hline \multirow[b]{2}{*}{ Shot \# } & \multirow[b]{2}{*}{$\begin{array}{c}\text { Gauge } \\
\text { location: }\end{array}$} & \multirow[b]{2}{*}{$\begin{array}{l}\text { Stand-off } \\
\text { distance, } \\
\mathrm{m}\end{array}$} & \multicolumn{2}{|c|}{$\begin{array}{c}1 \text { kg spherical } \\
\text { Nitromethane charge } \\
\text { (measured) }\end{array}$} & \multicolumn{2}{|c|}{$\begin{array}{c}1 \text { kg spherical TNT } \\
\text { charge } \\
\text { (Kingery-Bulmash } \\
\text { model, free-air burst) }\end{array}$} & \multicolumn{2}{|c|}{ Ratio NM / TNT } \\
\hline & & & $\begin{array}{c}\text { Peak } \\
\text { Incident } \\
\text { Pressure, } \\
\mathrm{kPa} \\
\end{array}$ & $\begin{array}{c}\text { Peak } \\
\text { Incident } \\
\text { Impulse, } \\
\text { kPa-msec }\end{array}$ & $\begin{array}{c}\text { Peak } \\
\text { Incident } \\
\text { Pressure, } \\
\mathrm{kPa} \\
\end{array}$ & $\begin{array}{c}\text { Peak } \\
\text { Incident } \\
\text { Impulse, } \\
\mathrm{kPa}-\mathrm{msec}\end{array}$ & $\begin{array}{l}\text { Incident } \\
\text { Pressure }\end{array}$ & $\begin{array}{l}\text { Incident } \\
\text { Impulse }\end{array}$ \\
\hline \multirow[t]{4}{*}{15} & $\# 1$ & 2.106 & 195.8 & 86.01 & 174.7 & 88.16 & 1.120 & 0.976 \\
\hline & $\# 2$ & 1.800 & 345.4 & 97.24 & 246.6 & 101.4 & 1.400 & 0.959 \\
\hline & $\# 3$ & 2.455 & 164.9 & 82.98 & 124.8 & 76.88 & 1.321 & 1.079 \\
\hline & $\# 4$ & 3.251 & 89.24 & 59.27 & 69.38 & 59.92 & 1.286 & 0.989 \\
\hline \multirow[t]{4}{*}{16} & $\# 1$ & 2.062 & 241.9 & 94.02 & 181.9 & 89.62 & 1.330 & 1.049 \\
\hline & $\# 2$ & 1.736 & 354.9 & 94.02 & 267.6 & 104.9 & 1.326 & 0.896 \\
\hline & \#3 & 2.401 & 162.0 & 84.09 & 130.3 & 78.26 & 1.243 & 1.074 \\
\hline & $\# 4$ & 3.227 & 89.02 & 63.16 & 70.41 & 60.32 & 1.264 & 1.047 \\
\hline \multirow[t]{4}{*}{17} & $\# 1$ & 2.032 & 218.5 & 94.27 & 187.9 & 90.81 & 1.163 & 1.038 \\
\hline & $\# 2$ & 1.768 & 285.2 & 100.41 & 256.8 & 103.1 & 1.111 & 0.974 \\
\hline & $\# 3$ & 2.436 & 159.2 & 81.87 & 126.3 & 77.27 & 1.260 & 1.060 \\
\hline & $\# 4$ & 3.253 & 93.19 & 61.41 & 69.29 & 59.89 & 1.345 & 1.025 \\
\hline & & & & & & Average & 1.26 & 1.01 \\
\hline
\end{tabular}

\section{Blast Impact Impulse Model (BIIM)}

392

The analytical approach is based on the model of instantaneous detonation of the spherical;

393 explosive charge located at a distance $h$ from the flat surface of the target. The assumed

394 mechanism of the expansion of the gas detonation products in vacuum behind the rarefaction

395 wave propagating with velocity $W$ is depicted in Figure 11. These assumptions are valid

396 within the distance $r_{0} \leq h \leq(10 \div 15) r_{0}$. Thus, for a 1-kg NM charge the analytical model of 
397 close-in detonation is expected to be valid for standoff distances up to 600-900 $\mathrm{mm}$ from the target surface.

399

400 401 402 403 404 405 406 407 408 409 inelastic collision.

412 The specific blast impulse acting on the target due to the flow through a stream tube with the 
413 cross-sectional area $d S$ can be determined using Eq.(1) as

$$
i=\frac{d I \cos \alpha}{d S}=\left(1+k_{r}\right) u_{0} \cos ^{2} \alpha \cdot \frac{d m}{d S}
$$

415 The coefficient of restitution for the gas particles can be determined by analyzing the limiting

416 case when the spherical charge is in contact with the target as this provides the known

417 pressure at the point of contact $(\alpha=0)$ equal to the mean detonation pressure $p_{0}=\rho_{0} u_{0} W$. It

418 has been shown [20] that the coefficient of restitution can be determined as

$$
k_{r}=\frac{W}{u_{0}}
$$

and, therefore Eq.(2) can be transformed to the following expression for the specific blast

421 impulse

$$
i=\left(W+u_{0}\right) \cdot \cos ^{2} \alpha \cdot \frac{d m}{d S}
$$

423 In Figure 12, $\Omega$ is the solid angle of a cone of expanding gas detonation products approaching

424 the target at the angle of incidence $\alpha$. From the definition of the solid angle, the area of a

425 spherical cap on the sphere with radius $r_{0}$ is defined as

$$
d S_{0}=r_{0}^{2} \Omega
$$

427 Hence, the mass of the detonation products within the cone of the gas detonation products can

428 be determined from the following expression

$$
d m=\frac{1}{3} d S_{0} r_{0} \rho_{0}=\frac{1}{3} \Omega r_{0}^{3} \rho_{0}
$$


430

431

434

435

436
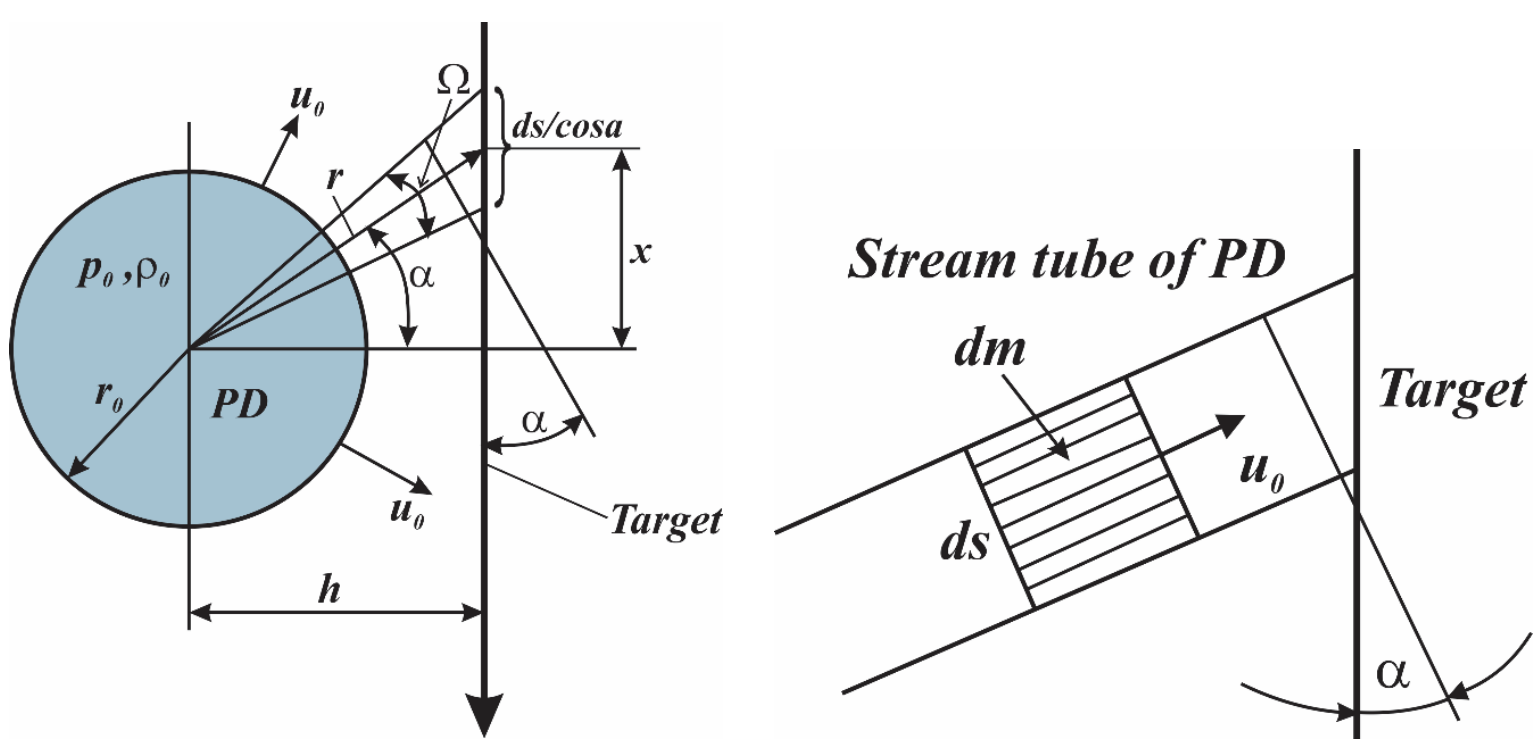

Figure 12. Model for calculating impulse of impinging detonation products for near-field blast loading conditions.

At a distance $r$ from the center of the charge, the cross-sectional area of the stream tube is determined as

$$
d S=r^{2} \Omega
$$

where $r=h / \cos \alpha$ and $\cos ^{2} \alpha=h^{2} / r^{2}$. Substituting these expressions into Eq.(4), we get the

following expression to calculate the specific blast impulse transferred to the target at a

distance $r$ from the center of the charge

$$
i(r)=\left(W+u_{0}\right) \cos ^{2} \alpha \cdot \frac{\Omega r_{0}^{3} \rho_{0}}{3 \Omega r^{2}}=\frac{W+u_{0}}{3} r_{0}^{3} \rho_{0} \frac{h^{2}}{r^{4}}
$$

where $W$ is the velocity of rarefaction wave in the detonation products, $u_{0}$ is the particle

velocity of the expanding detonation products flying away from the surface of the charge, $\rho_{0}$

is the initial density of the explosive material, $r_{0}$ is the radius of the spherical charge, $h$ is the distance from the center of the charge to the target, and $r$ is the distance from the center of the charge to a position on the target where the blast impulse is determined. 
446 Eq.(8) can be transformed to a more convenient form for predicting the blast impulse at any

447 location on the target plate by taking into account that the spherical charge mass

$448 C=4 / 3 \pi r_{0}^{3} \rho_{0}$ and $r^{4}=\left(h^{2}+x^{2}\right)^{2}$. Hence,

$$
i(x)=\frac{\left(W+u_{0}\right) C}{4 \pi} \cdot \frac{h^{2}}{\left(h^{2}+x^{2}\right)^{2}}
$$

450 Figure 13 depicts the distributions of blast impulses over the steel plate for two standoff

451 distances of $110 \mathrm{~mm}$ and $150 \mathrm{~mm}$ as predicted by the analytical model of close-in detonation.

452 From Figure 13, one can notice that the blast loads acting on the steel plates are highly

453 localized with about 80-90 percent of the blast energy being transferred to the steel plates

454 within a radius of $150 \mathrm{~mm}$ from the center. This fact will be used later for simplified

455 engineering modelling of the steel plate response for close-in high explosive detonations.

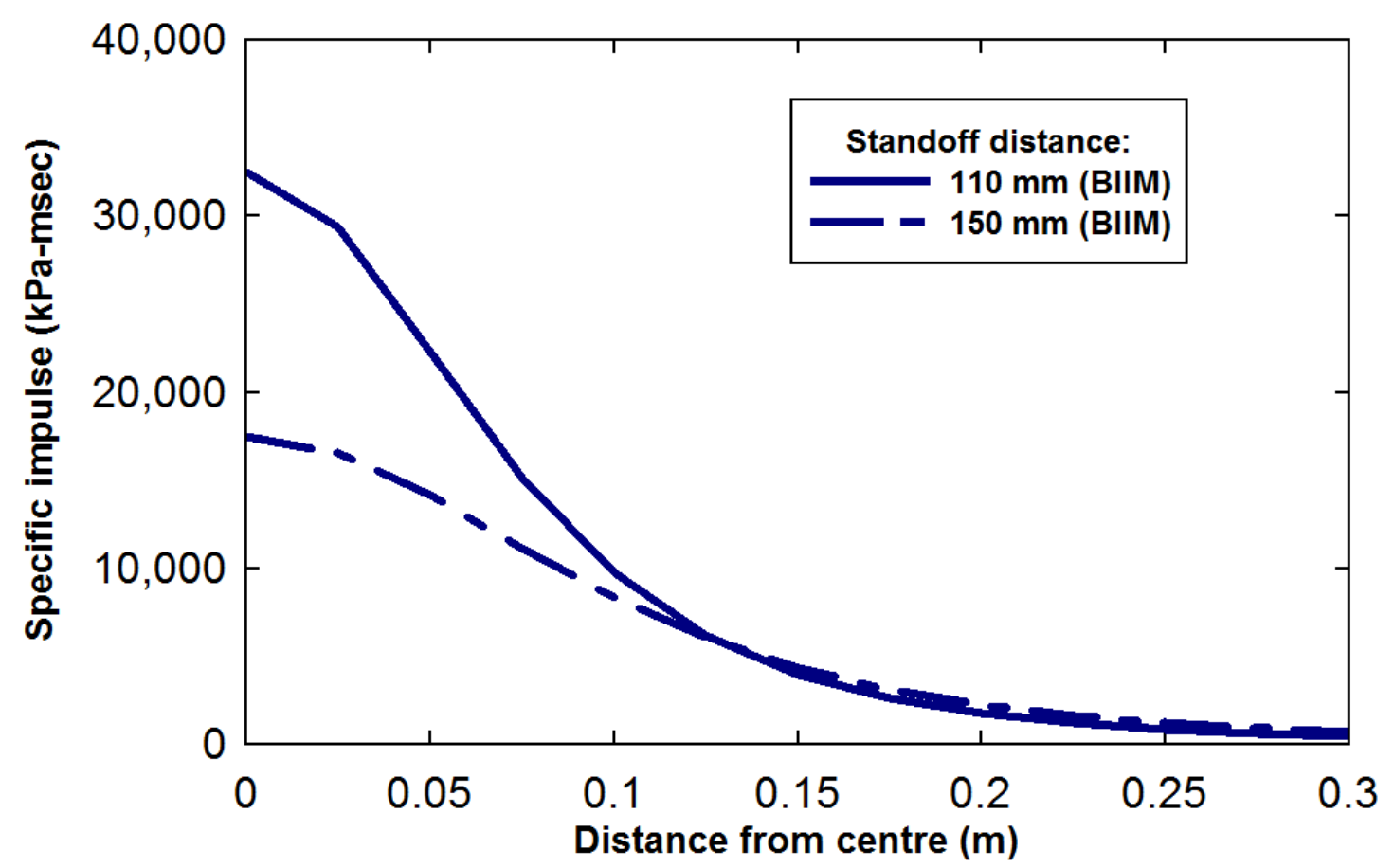

456

Figure 13: Blast impulse predictions using BIIM model of close-in detonation. 
459 In order to validate the blast loads predicted by the analytical model of close-in detonation,

460 the analytical blast impulses will be applied to the MS, HS, and SS steel plates to determine

461 their dynamic response and compare with the experimental data for these plates.

462

463

\section{Simulation of response of steel plates using Blast Impact Impulse Model (BIIM)}

464

\subsection{Initial nodal velocities to simulate blast impact}

465 The three types of steel plates were modelled using the finite element program LS-DYNA.

466 The steel plates were modelled using 4-node Belytschko-Tsai reduced integration shell

467 elements. The steel plate model size was 700 x $700 \mathrm{~mm}$. The model was fully restrained on all

468 four edges. Similar to the "blast impact" approach introduced by Remennikov and Uy [2] for

469 modelling close-in explosion loading on the steel tubular columns, the blast impulses

470 calculated using the analytical model for the plate nodes were converted to the initial velocity

471 boundary conditions applied to the nodes of the steel plate. The initial nodal velocities were

472 estimated using the specific blast impulse from Eq.(9) and the tributary mass areas to the

473 nodal points of the plate as

474

$$
v_{0}(x)=\frac{i(x)}{\rho_{p l} t_{p l}}
$$

475 where $\rho_{p l}$ is the density of material and $t_{p l}$ is the thickness of the steel plate. The initial

476 velocities were calculated for the standoff distances $110 \mathrm{~mm}$ and $150 \mathrm{~mm}$ and their

477 distribution over the plate is shown in Figure 14. The calculated initial nodal velocities were 
478 applied to the nodes using *INITIAL_VELOCITY_NODE command in LS-DYNA as 479 demonstrated in Figure 15.

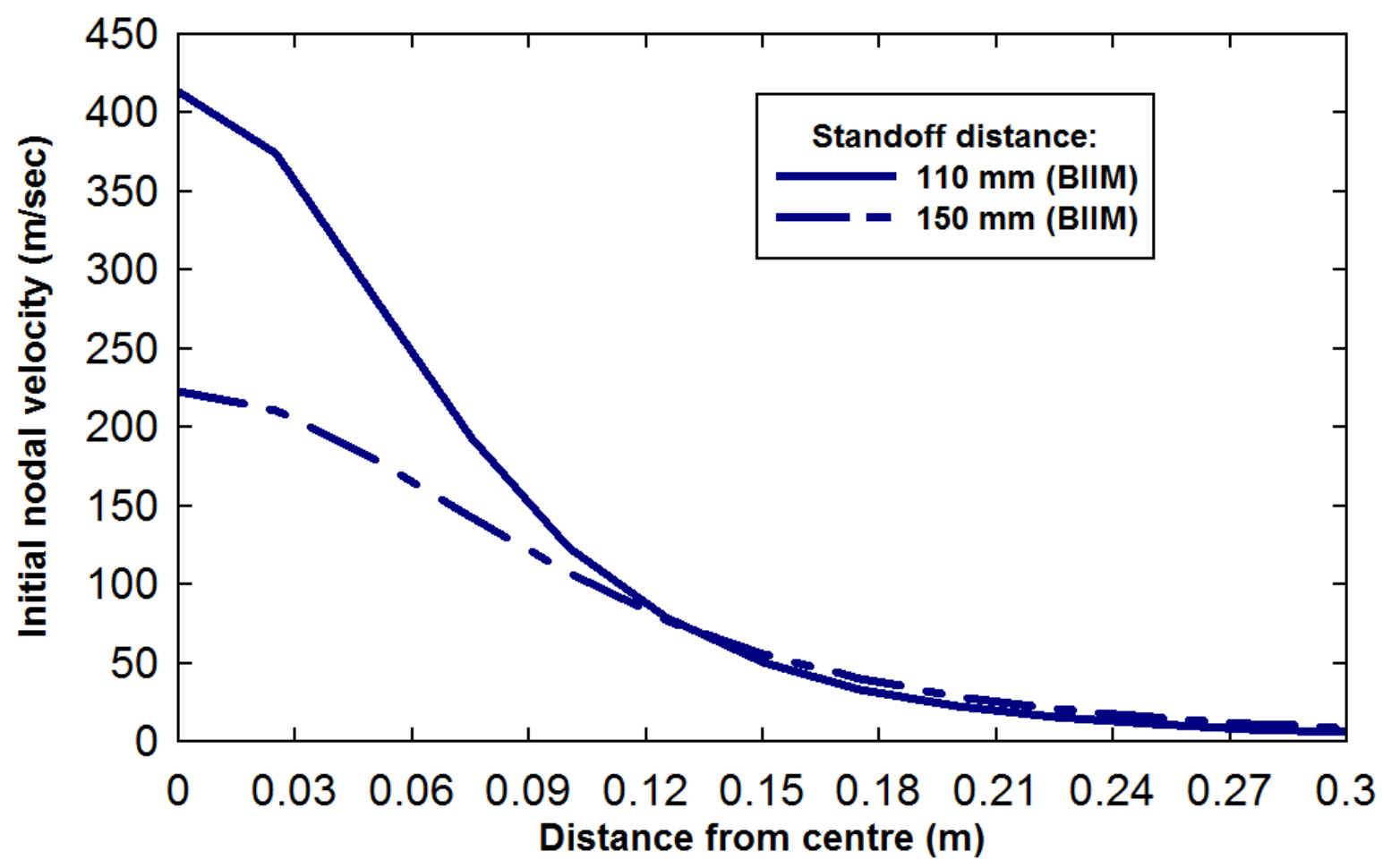

480

481 Figure 14: Distribution of initial nodal velocities for standoff distances $110 \mathrm{~mm}$ and $150 \mathrm{~mm}$. 482 483 $10 \mathrm{~mm}$ Steel Plate $1.0 \mathrm{~kg}$ Nitromethane $150 \mathrm{~mm}$ standoff Vectors of Z-velocity $\min =0$, at node\# 1
$\max =223000$, at node
421
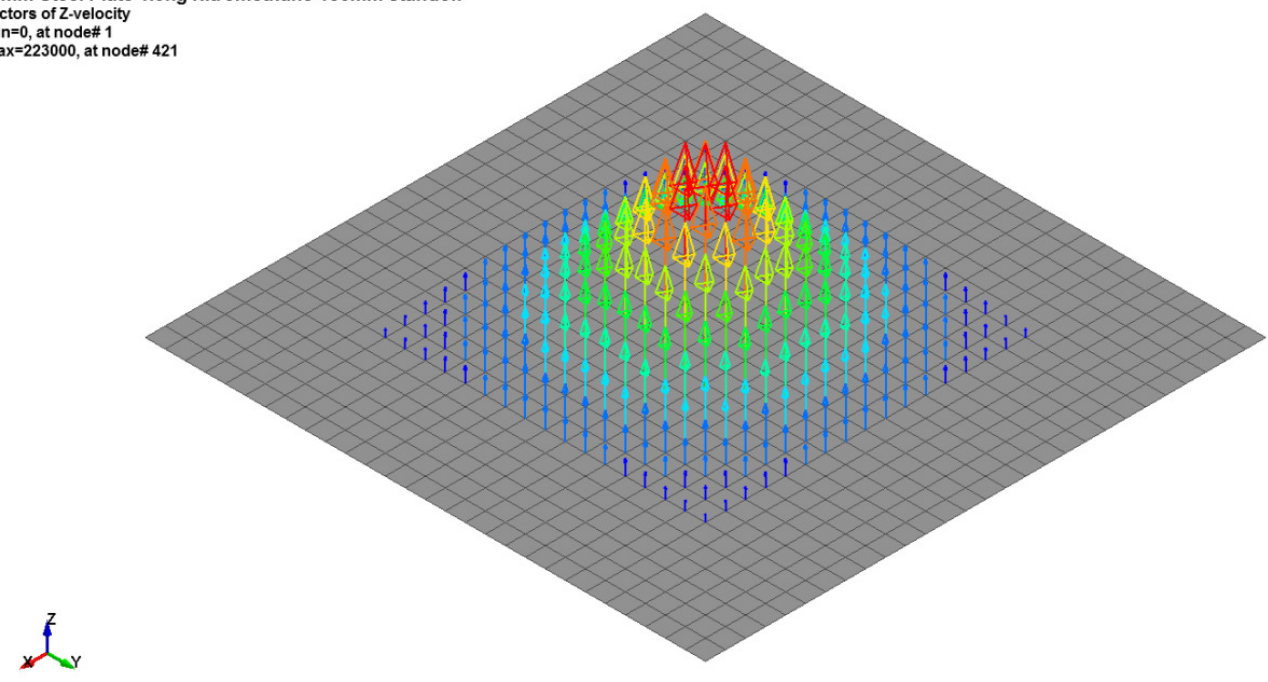

Figure 15: Vectors of initial nodal velocities for $1 \mathrm{~kg} \mathrm{NM}$ charge at $150 \mathrm{~mm}$ standoff. 
487 Severe impact of impinging detonation products on the steel plate will produce a rate of 488 deformations in the material several orders of magnitude higher than that under quasi-static 489 loading conditions. Strain-rate hardening effects in the finite element computations were 490 considered using two models. The Johnson-Cook model [15] was previously used by 491 Ackland et al. [6] for modelling response of the similar mild steel plates XLERPLATE 350 492 under close-in detonation. Various attempts to use the Johnson-Cook parameters from [6] 493 with the proposed BIIM model were unsuccessful in generating reasonable predictions of the 494 steel plate response. Instead, strain-rate hardening was incorporated using the 495 Cowper-Symonds strain hardening model [16], which scales the yield stress as shown

$$
\sigma_{y d}=\sigma_{y}\left[1+\left(\frac{\dot{\varepsilon}}{C}\right)^{\frac{1}{p}}\right]
$$

497 where $\sigma_{y}$ is the yield stress at constant rate, $\sigma_{y d}$ is the dynamic yield stress, $\dot{\varepsilon}$ is the effective 498 strain rate, and $C$ and $p$ are strain rate coefficients to be determined based on test data. Table 7 499 presents coefficients for the Cowper-Symonds model. According to Paik and Thayamballi 500 [14], the Cowper-Symonds coefficients for Mild steel in Table 7 were determined 501 experimentally using the steels with yield stresses between 189.6 MPa and 283.0 MPa, and 502 for High tensile steel the yield stresses were between 313.8 MPa and 522.9 MPa. Hence, in 503 this numerical study the Cowper-Symonds coefficients $C=32001 / \mathrm{sec}$ and $p=5$ were 504 adopted for modelling high-strain rate effects for MS and HS steel plates. 
506 Table 7. Sample coefficients for the Cowper-Symonds equation [14].

\begin{tabular}{|l|l|l|l|}
\hline Material & $C(1 / \mathrm{s})$ & $p$ & \multicolumn{1}{c|}{ Reference } \\
\hline Mild steel & 40.4 & 5 & Cowper \& Symonds [16] \\
\hline High tensile steel & 3200 & 5 & Paik et al.[17] \\
\hline Stainless steel 304 & 100 & 10 & Forrestal \& Sagartz [18] \\
\hline
\end{tabular}

507

508 Figure 16 presents the time histories for the mild steel plates MS-1 and MS-2 subjected to an

509 impulsive load from a 1-kg NM spherical charge at $110 \mathrm{~mm}$ and $150 \mathrm{~mm}$ standoff calculated

510 by LS-DYNA using the initial nodal velocities presented in Figure 15. Figure 17 compares

511 the time history of the response of the high strength steel plate HS-2 with the experimental

512 residual deformation. It can be noticed that the predicted residual deformations for all

513 analyses steel plates match the experimental values very closely which can be used to validate

514 the loading predicted by the BIIM.

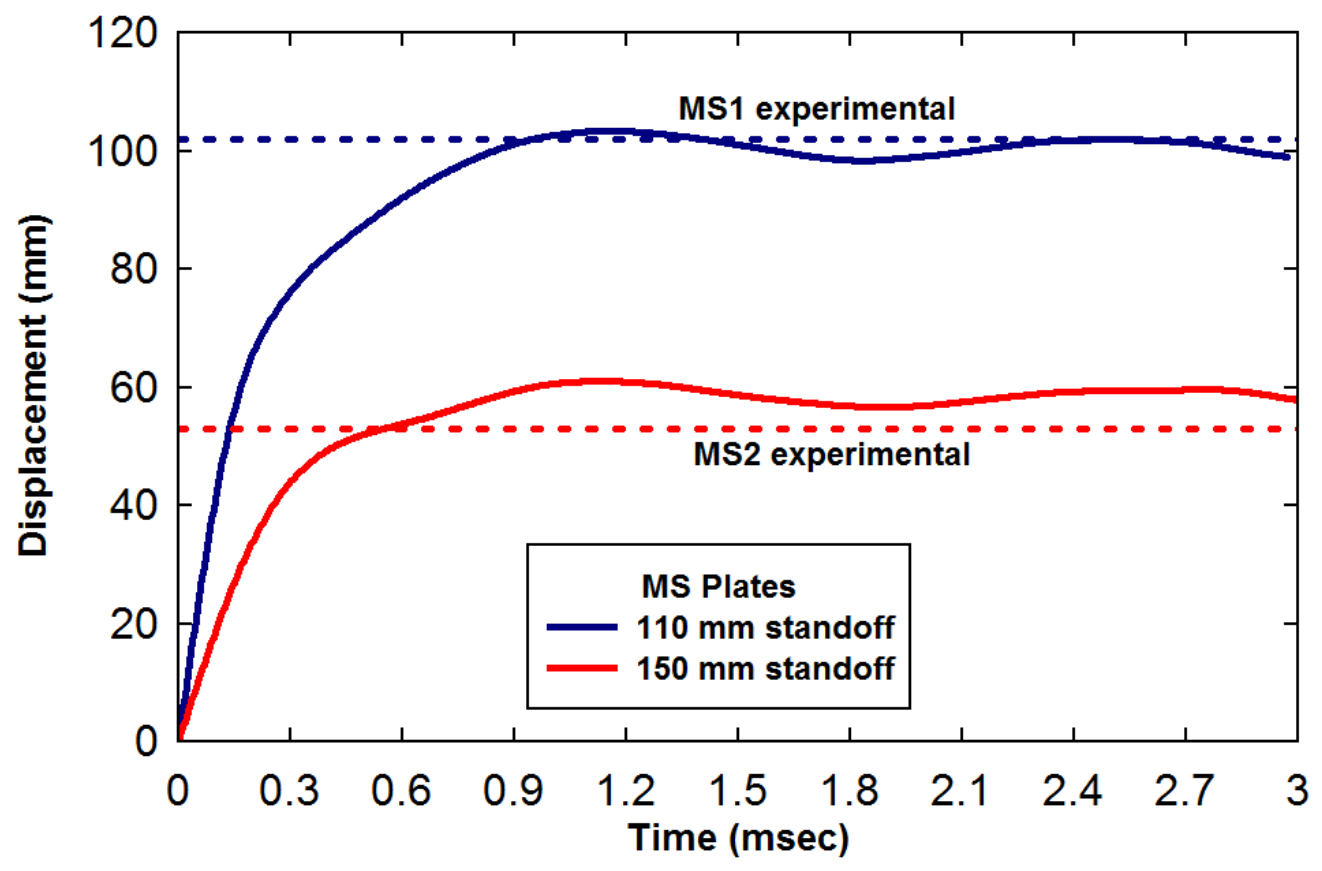

516 Figure 16: Comparison of displacement time histories predicted by the BIIM loading model 


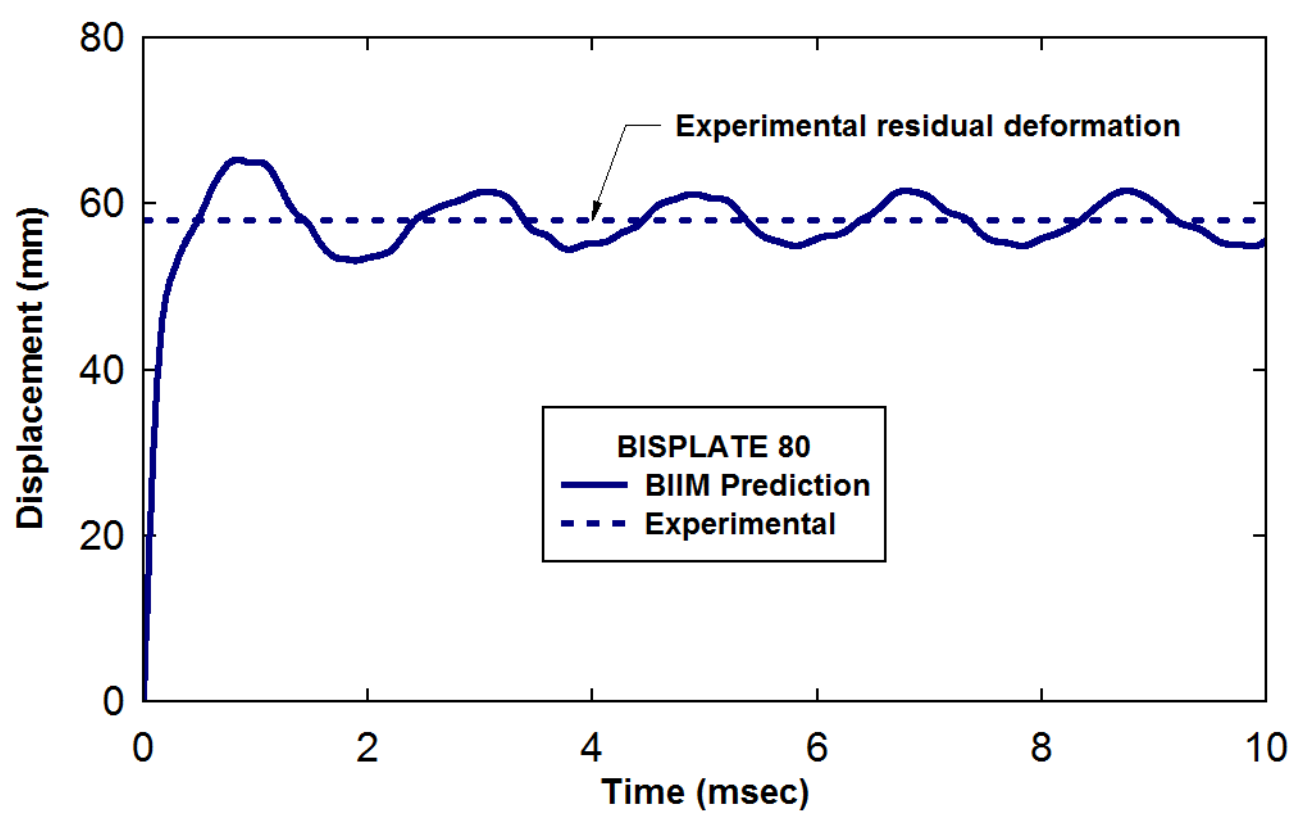

520 Figure 17: Comparison of displacement time histories predicted by the BIIM loading model with experimental residual deformation of HS-2 plate.

\section{Summary and conclusions}

524 An explosive field trial was conducted to investigate the response of steel plates due to

525 close-in blast loading from high explosives. The aim of the testing program was to subject the

526 steel plates to blast loading from $1 \mathrm{~kg}$ NEQ TNT spherical charges. This was achieved by

527 employing sensitized nitromethane as the liquid high explosive and manufacturing plastic

528 spherical charge casings using 3-D printing technology.

529 The responses of three types of steel plates, namely mild steel Grade 350, high strength steel, and stainless steel Grade 304 were determined to the near-field blast loading conditions.

531 The performance of the plates was assessed based on the final deformation profiles that were 
532 determined using 3-D scanning of the deformed steel plates. The mild steel plates resulted in

533 the highest residual plate deformations. High-strength steel BISPLATE 80 plates

534 demonstrated $60 \%$ reduction in the peak deformation compared to the mild steel plates.

535 Stainless steel Grade 304 plates achieved 26\% reduction in the peak deformations compared

536 to the mild steel plates.

537 Experimental investigation was conducted to evaluate the effect of spray-on polyurea

538 coating applied to the front and back surfaces of the plates subjected to the near-field blast

539 loading. Steel plates were sprayed with two thicknesses of polyurea coating of $6 \mathrm{~mm}$ and 12

$540 \mathrm{~mm}$. It was evidenced that there was no considerable mitigation effect on the peak

541 deformations of the steel plates with the $6 \mathrm{~mm}$ polyurea coating applied on the front face

542 compared to the bare steel plates. It was also observed that polyurea layer melted near the

543 center of the plate due to the excessive heat of the detonation gases which may have affected

544 the overall effectiveness of polyurea coating in reducing deformation response of the steel

545 plate to the close-in blast loads. The effect of $12 \mathrm{~mm}$ coating applied to the back surface of the

546 steel plates was more pronounced in terms of reducing overall damage, in particular in

547 combination with replacing the material from mild steel to high strength steel.

548 The Blast Impact Impulse Model (BIIM) is presented in this paper for predicting the blast

549 impulse for close-in detonation of a spherical explosive charge. The model is based on the

550 hypothesis of instantaneous detonation that was presented by the authors in their work on

551 explosive breaching of concrete walls [21]. Under the condition of instantaneous detonation, 
552 all explosive charge particles are assumed to stay stationary and hold the original volume of

553 the explosive charge. After the instantaneous detonation, the gas detonation products begin to

554 expand. The particles located on the outer surface of the charge begin flying away first.

555 Following the outer surface particles, the particles located on the successive interior surfaces

556 start progressively flying away so that the boundary between the moving particles and the

557 stationary particles is moving inside the charge with some velocity. This paper presents the

558 original derivation for the specific blast impulse acting on the target in the close proximity

559 from the charge. The BIIM allows for rapid generation of the blast effects on the targets due to

560 close-in detonations by converting the specific blast impulses into the initial velocity

561 boundary conditions applied to the nodes of the steel plate. The predicted residual

562 deformations for all analyzed steel plates matched the experimental values very closely which

563 contributes to the validation studies of the engineering-level modelling of close-in blast

564 loading effects on structures undertaken by the authors in the previous studies.

565 One of the objectives of the trial was to better understand the effect of different

566 approaches to positioning spherical charges at the required close-range standoff distance. It

567 was experimentally confirmed that the blast energy of a spherical charge can be transformed

568 and focused by the tubular supporting elements made from such weak media as cardboard.

569 This effect requires further investigation and may find applications in military and civilian

570 situations where target localized penetration with small charges may be required. 
573 The support of Mr Arran Gordon of Havoc Industries with organizing and carrying out the

574 blast trials is gratefully acknowledged. The authors also wish to thank Mr Alan Grant and $\mathrm{Mr}$

575 Cameron Neilson of the University of Wollongong for their assistance with preparing test

576 specimens and technical support during the blast trials.

577

578 References

579 [1] Ngo T, Mohotti D, Remennikov AM, Uy B. Numerical simulations of response of 580 tubular steel beams to close-range explosions. Journal of Constructional Steel Research $2015 ; 105: 151-163$.

582 [2] Remennikov AM, Uy B. Explosive testing and modelling of square tubular steel columns for near-field detonations. Journal of Constructional Steel Research 2014; 101: 290-303.

[3] Karagiozova D, Yu T, Lu G. Transverse blast loading of hollow beams with square cross-sections. Thin-Walled Structures 2013; 62:169-178.

[4] Jama H, Nurick G, Bambach M, Grzebieta R, Zhao X. Steel square hollow sections subjected to transverse blast loads. Thin-Walled Structures 2012; 53:109-122.

[5] Raman SN, Ngo T, Mendis P, Pham T. Elastomeric polymers for retrofitting of reinforced concrete structures against the explosive effects of blast. Advances in Materials Science and Engineering, 2012. 
592 [6] Ackland A, Anderson C, Ngo T. Deformation of polyurea-coated steel plates under 593 localised blast loading. International Journal of Impact Engineering 2013; 51:13-22.

594 [7] Mohotti D, Ali M, Ngo T, Lu J, Mendis P. Strain rate dependent constitutive model for predicting the material behaviour of polyurea under high strain rate tensile loading. Materials and Design 2014; 53:830-837.

[8] Mohotti D, Ngo T, Mendis P, and Raman SN. Polyurea coated composite aluminium plates subjected to high velocity projectile impact. Materials and Design 2013; 52: $1-16$.

600

[9] Tekalur SA, Arun S, and Kunigal S. Blast resistance of polyurea based layered

601 composite materials. Composite Structures 2008; 84:271-281.

602 [10] Ritzel D. Personal communications. October 2014.

603 [11] Dusenberry DO. Handbook for blast resistant design. John Wiley \& Sons, 2010.

604 [12] Netherton MD, Stewart MG, Lyons SJ, Blanford NW, Papp S. \& Pleasance LM. 605 Experimental data from 2012 repeatable explosive field trials, Research Report, Centre Australia. October 2014, http://hdl.handle.net/1959.13/1056125.

608 [13] Neuberger A, Peles S, Rittel, D. Scaling the response of circular plates subjected to 609 large and close-range spherical explosions. Part I: Air-blast loading, International Journal of Impact Engineering 2007; 34:859-873.

611 [14] Paik JK, Thayamballi AK. Ultimate limit state design of steel plated structures. John 
613 [15] Johnson GR, Cook WH. A constitutive model and data for metals subjected to large 614 strains, high strain rates and high temperatures. Proceedings of the 7th International 615 Symposium on Ballistics, The Hague, The Netherlands, April 1983.

616 [16] Cowper GR, Symonds PS. Strain hardening and strain rate effects in the impact loading of cantilever beams. Brown University, Applied Mathematics Report, 1958.

618 [17] Paik JK, Chung JY, Paik, YM. On dynamic/impact tensile strength characteristics of thin high tensile steel materials for automobiles. Journal of Korea Society of Automotive Engineers 1999; 7: 268-278.

621

[18] Forrestal MJ, Sagartz MJ. Elastic-plastic response of 304 stainless steel beams to impulse loads. J. Appl. Mech. 1978; 45: 685-687.

623 [19] Kingery CN, Bulmash G. Airblast parameters from TNT spherical air bursts and hemispherical surface bursts, ARBRL-TR-02555, April 1984.

625 [20] Salamakhin TM. Fundamentals of mechanical effects of explosion on structures and 626 methods of predicting blast loads. Moscow, Military Engineering Academy Publication (in Russian), 1974.

628 [21] Remennikov AM, Mentus I, Uy, B. Explosive breaching of walls with contact charges: theory and applications. International Journal of Protective Structures 2015; 6:629-647. 